EUROPEAN CENTRAL BANK

WORKING PAPER SERIES

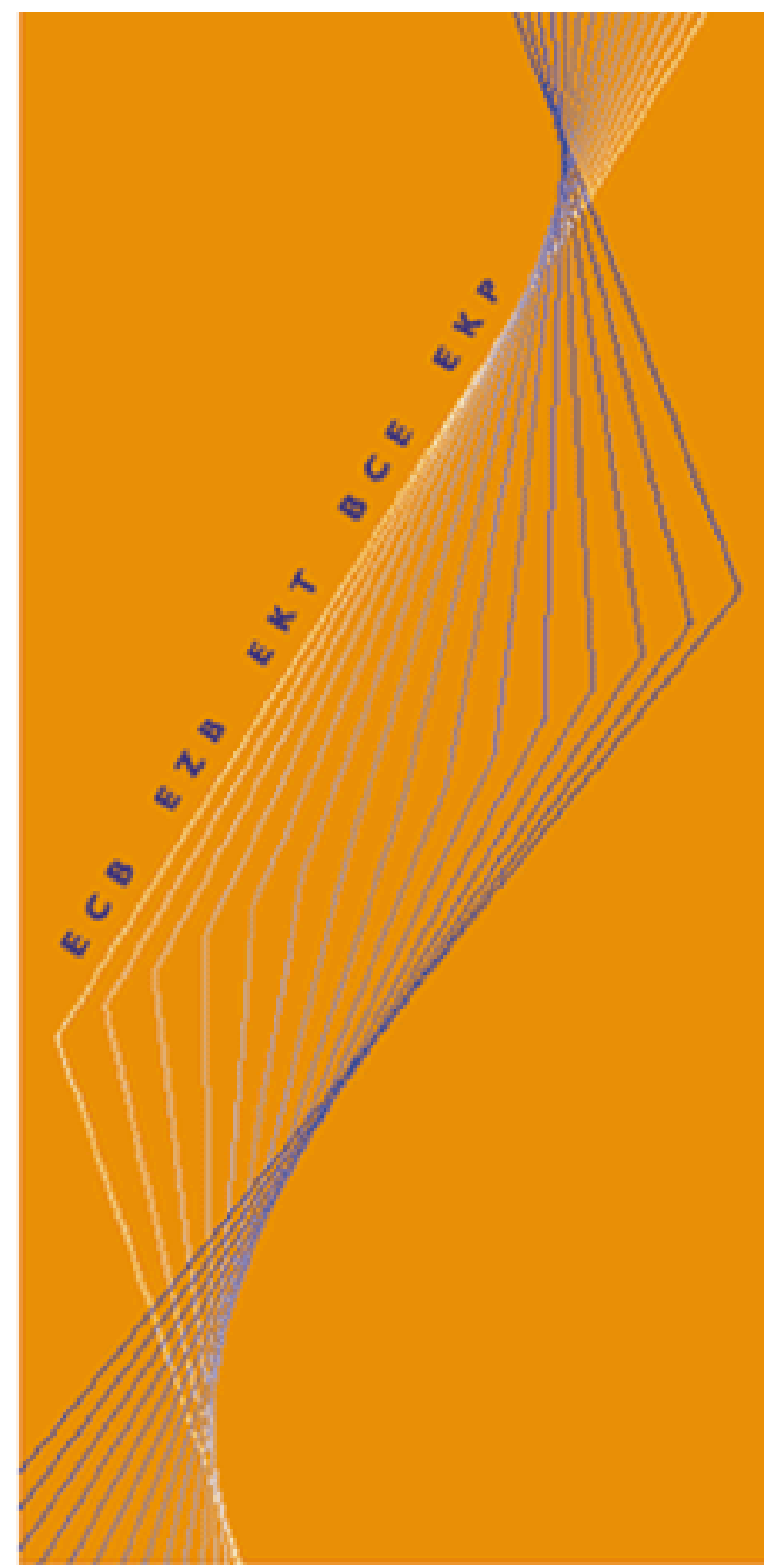

WORKING PAPER NO. 166

MONETARY AND FISCAL POLICY INTERACTIONS IN A MICRO-FOUNDED MODEL OF A MONETARY UNION

BY ROEL M.W.J. BEETSMA

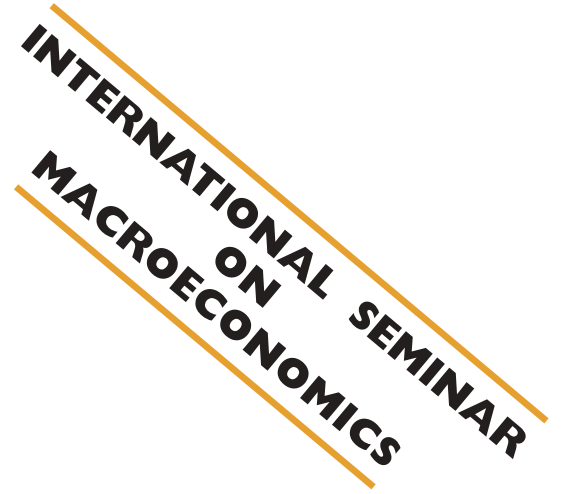
AND HENRIK JENSEN 


\section{WORKING PAPER SERIES}

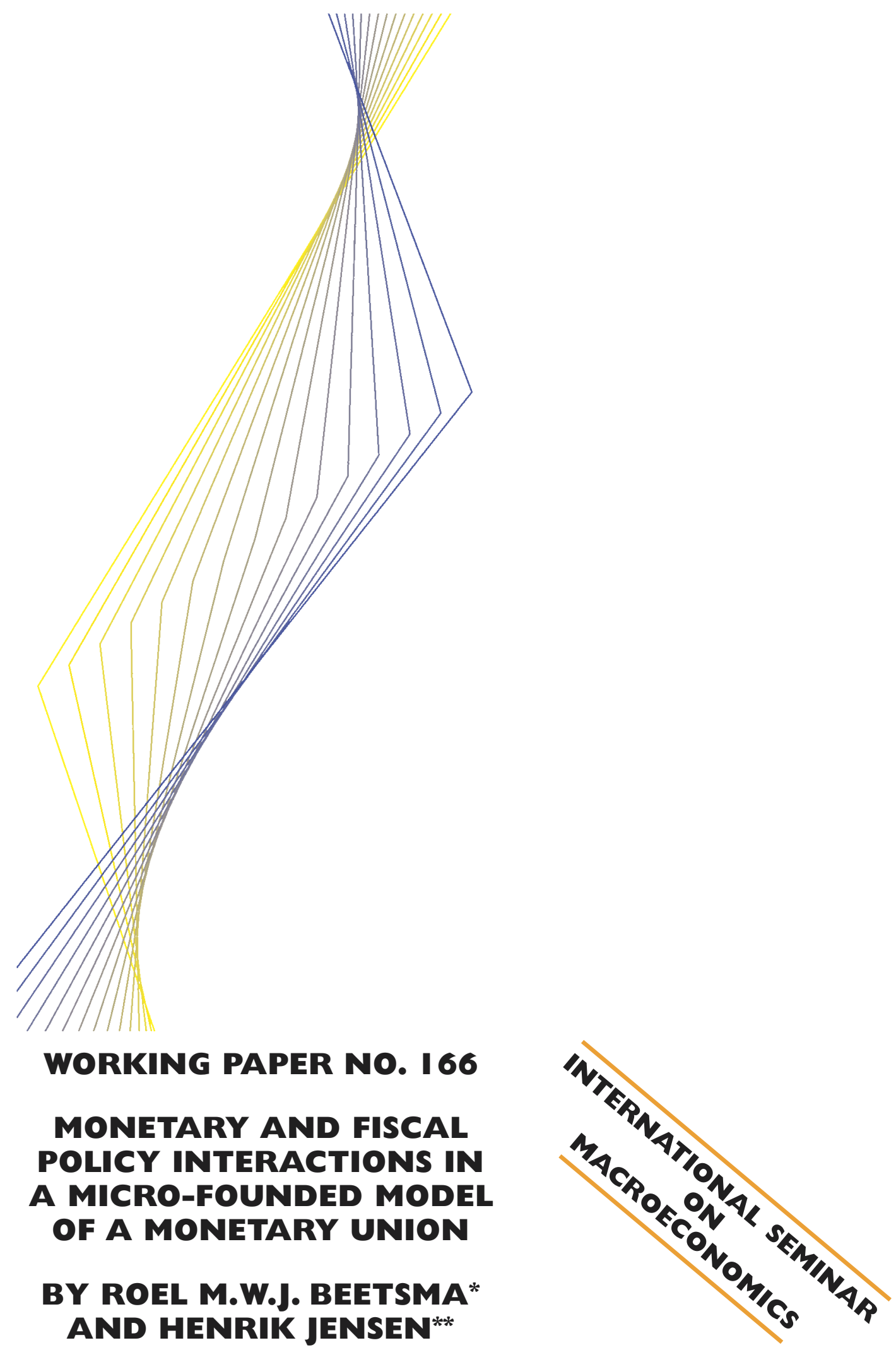

August 2002

We thank Peter Ireland, Volker Wieland and participants at the ISOM conference at the European Central Bank for very helpful comments and suggestions. The usual disclaimer applies. Jensen thanks EPRU for financial support (the activities of EPRU are financed by a grant from the Danish National Research Foundation). This paper was presented at the NBERIEEA International Seminar on Macroeconomics organised by Jim Stock and Lars Svensson and hosted by the European Central Bank on 5-6 June 2002.

* University of Amsterdam and CEPR. Mailing address: Department of Economics, University of Amsterdam, Roetersstraat II, I0 I8 WB Amsterdam, The Netherlands. Phone: +3I.20.5255280; fax: +31.20.5254254; email: Beetsma@fee.uva.nl.

** University of Copenhagen, CEPR and EPRU. Mailing address: Institute of Economics, University of Copenhagen, Studiestraede 6, DKI455 Copenhagen, K, Denmark. Phone: +45.35.323043; fax: +45.35.323000; email: Henrik.Jensen@econ.ku.dk. Web: www.econ.ku.dk/personal/henrikjl 
(C) European Central Bank, 2002

\begin{tabular}{|c|c|}
\hline \multirow[t]{2}{*}{ Address } & Kaiserstrasse 29 \\
\hline & D-603 I I Frankfurt am Main \\
\hline & Germany \\
\hline \multirow[t]{3}{*}{ Postal address } & Postfach 160319 \\
\hline & D-60066 Frankfurt am Main \\
\hline & Germany \\
\hline Telephone & +496913440 \\
\hline Internet & http://www.ecb.int \\
\hline Fax & +496913446000 \\
\hline Telex & 4|| I44 ecb d \\
\hline
\end{tabular}

All rights reserved.

Reproduction for educational and non-commercial purposes is permitted provided that the source is acknowledged.

The views expressed in this paper are those of the authors and do not necessarily reflect those of the European Central Bank.

ISSN I56I-08I0 


\section{Contents}

$\begin{array}{ll}\text { Abstract } & 4\end{array}$

Non-technical summary 5

$\begin{array}{ll}\text { I Introduction } & 7\end{array}$

2 The model 9

2.I Utilities and private consumption 9

2.2 Firms II

3 Equilibrium $\quad 12$

$\begin{array}{ll}\text { 3.I Efficient steady state and flexible price equilibrium } & 12\end{array}$

$\begin{array}{ll}3.2 & \text { Equilibrium dynamics under sticky prices }\end{array}$

$4 \quad$ Setup of the policy analysis $\quad 17$

4.I The objective function 17

$\begin{array}{lll}4.2 & \text { The policies } & 18\end{array}$

4.3 The benchmark parameter combination 19

5 Discussion of the (numerical) results 21

5.I The optimal policies $\quad 22$

5.2 The rules 25

$\begin{array}{llr}6 & \text { Conclusion } & 27\end{array}$

$\begin{array}{ll}\text { Appendices } & 29\end{array}$

$\begin{array}{ll}\text { References } & 36\end{array}$

European Central Bank working paper series $\quad 39$

ECB • Working Paper No $166 \cdot$ August 2002 


\begin{abstract}
So far, the "new open economy macroeconomics" literature has primarily focused on monetary policy and monetary policy rules, rather than paying attention also to fiscal policy. This is an omission because, especially with the advent of EMU, the burden on fiscal policy as an instrument for macroeconomic stabilization has potentially increased. In this paper, we focus on the interactions between monetary and fiscal policy in a micro-founded model of a monetary union. By extending a two-country, New-Keynesian model with public spending, we find that the forwardlooking Phillips curves depend on consumption, terms-of-trade and public spending deviations from their respective stochastic natural rates. We study the optimal coordinated monetary and fiscal policies for various settings. We also consider simple monetary and fiscal policy rules and investigate to what extent these rules can approximate the optimal solution under commitment.
\end{abstract}

Keywords: Policy mix; monetary policy rules; fiscal policy rules; monetary union.

JEL codes: E52, E61, E62, E63, F33 


\title{
Summary of "Monetary and Fiscal Policy Interactions in a Micro-founded Model of a Monetary Union"
}

\author{
by Roel Beetsma and Henrik Jensen
}

An extensive amount of work has now been done on monetary policy in micro-founded models with sticky prices. However, this literature has so far paid little attention to the role of fiscal policy in multiple-country versions of these models and how fiscal policy and monetary policy interact in the stabilization of shocks. In the context of European Monetary Union (EMU) the issue of the interaction between monetary and fiscal policy is important for a variety of reasons. Some of the relevant questions are the following: to what extent will the burden of country-specific shock stabilization on fiscal policy increase? Will fiscal constraints hamper stabilization? Is there is a need for the coordination of monetary and fiscal policies in macro-economic stabilization?

In this paper, we try to address the above-mentioned gap in the literature by combining monetary and fiscal policy in a micro-founded, two-country model of a monetary union. The framework extends a recent model developed by Benigno (2001). We derive the dynamics of the two economies assuming that prices adjust only slowly and that, in addition to a common monetary policy, there are national fiscal authorities pursuing active stabilization policies using public spending.

Throughout the paper the objective is to maximize the welfare of the entire union. This is obvious for the common central bank. However, given that in Europe there is a discussion about the need to coordinate (fiscal) policies, it is interesting to take also a supra-national perspective when evaluating the performance of fiscal policies and see how one could design policies that best serve the common interest. First, we study the optimal commitment and discretionary policies. Here, we allow for both full optimization over all instruments (monetary and fiscal) and for the case where fiscal policy is "passive". In the latter case, fiscal policies are at their natural levels, because they are exclusively directed at the efficient provision of public goods and take no part in macroeconomic stabilization.

The optimal policies exhibit a number of interesting features. First, in the absence of asymmetries in price rigidity, the optimal monetary policy closes the world consumption gap and forces world inflation to be zero. ${ }^{1}$ While world inflation is zero, supply shocks generally cause national producer inflation rates to differ from zero. The role of the optimal fiscal policy is then to trade off the resulting terms-of-trade gap against national inflation rates and government spending gaps. Only in the special case of perfectly correlated supply shocks can the optimal policy mix replicate the efficient flexprice allocation. In that case, the natural rate of the terms of trade is constant, thereby leaving national inflation rates perfectly stable with public spending levels at their natural rates. Second, with equal degrees of price rigidity throughout the monetary union, monetary policy is not subject to a time-consistency problem, while fiscal policy does suffer from such a problem. As a result, there are welfare gains to be obtained from the commitment of fiscal policy. In particular, by committing to a public spending pattern

\footnotetext{
${ }^{1}$ By "world" we mean the (weighted) average over the two countries. Further, a "gap" refers to the deviation of a variable from its stochastic natural rate (i.e., the level under the efficient flexible-price equilibrium).
} 
that involves more active stabilization, the common policy-maker influences inflation expectations in a way that improves the inflation/public spending trade off, thereby securing more stable national inflation rates and a more stable terms-of-trade gap. Finally, with differences in price rigidity, the optimal common monetary policy puts a relatively large emphasis on stabilizing the inflation of the country with the highest degree of price rigidity. Hence, the other country is characterized by more variable inflation and employs a more active fiscal stabilization policy.

While it is often argued that monetary unification shifts the burden of stabilizing country-specific shocks to fiscal policy, it turns out that in our model the relative advantage of using fiscal stabilization policy is unchanged when the correlation of the supply shocks decreases. The linear-quadratic structure of the model ensures that the public spending gap always offsets a given fraction of the macroeconomic fluctuations.

From a welfare point of view, the use of fiscal policy for stabilization appears to be of relevance. Restricting fiscal policy to be equal to its natural level leads to welfare losses that, for the parameter combinations that we consider, are equal to a permanent reduction in consumption of the order of 0.5 to 1 percentage point.

We also explore several types of simple policy rules. It is sometimes argued that the advantage of such rules is that they are relatively simple to understand and transparent. As a result, it may be easier to commit to them than to the optimal policy. We explore rules that have monetary policy close the world consumption gap as much as possible and keep world inflation as close as possible to zero (so as to approximate the properties of the optimal monetary policy). Expected welfare losses can then be reduced further if the public spending gap is made to respond to the terms-of-trade gap, thereby stabilizing national inflation. In particular, a terms-of-trade deterioration should lead to a fiscal contraction. This combination of simple policy rules is able to reduce the expected loss below that under full optimization with discretion. It cannot, however, attain the loss under the optimal commitment policy. We find a "distance" to the loss under optimal commitment that is equivalent to a permanent reduction in consumption ranging from 0.3 to 0.6 percentage points.

We also consider a standard Taylor-rule for monetary policy combined with fiscal policy rules that make the public spending gap a linear function of the output gap. Such a combination of rules generally performs well and produces expected losses below those under full optimization with discretion. In fact, the expected losses are surprisingly close to those obtained under the set of rules described in the previous paragraph (i.e., those approximately featuring the optimal monetary policy). The optimal fiscal rules are counter-cyclical and for our baseline parameter combination a 1\%-point increase in the output gap causes a fall in the spending gap of somewhat more than 1\%-point.

\section{Reference}

Benigno, P., 2001, Optimal Monetary Policy in a Currency Area, mimeo, New York University. 


\section{Introduction}

An extensive amount of work has now been done on monetary policy in micro-founded models with sticky prices. ${ }^{1}$ However, this literature has so far paid little attention to the role of fiscal policy in multi-country versions of these models and how monetary and fiscal policy interact in the stabilization of shocks. Early work on standard micro-founded models for fiscal policy in multi-country models includes, for example, Turnovsky (1988) and Devereux (1991). Among recent papers on monetary policy with micro-foundations and sticky prices that also include fiscal policy are Schmitt-Grohé and Uribe (2001) for a closed economy and Corsetti and Pesenti (2001a) in the context of a two-country model. In the context of European Monetary Union (EMU) the issue of the interaction between monetary and fiscal policy is of particular importance for a variety of reasons. Key questions are whether fiscal policy should be more active in stabilizing country-specific shocks now that monetary policy can no longer address these shocks and whether fiscal constraints (such as the Stability and Growth Pact) hamper stabilization.

In this paper, we try to address the abovementioned gap in the literature by combining monetary and fiscal policy in a micro-founded, two-country model of a monetary union. ${ }^{2}$ Our framework extends a recent model developed by Benigno (2001). We derive the dynamics of the two economies assuming that prices adjust only slowly and that, in addition to a common monetary policy, there are national fiscal authorities pursuing active stabilization policies using public spending. The supply-side features forward-looking Phillips curves, with inflation not only driven by the terms of trade and consumption, as in Benigno (2001), but also by public spending. Given that in Europe there is an increasing discussion about the need to coordinate fiscal policies, we assume that the latter are set in a coordinated fashion, with the aim of maximizing welfare at the union level.

As a benchmark, we explore the optimal monetary and fiscal policies when the authorities can commit and countries are characterized by equal degrees of price rigidity. The optimal monetary policy ensures that both union-wide inflation and consumption are at their natural (efficient) levels. While monetary policy in this special, symmetric case does not face a stabilization trade-off and is not subject to a time-consistency problem, fiscal policy is subject to such a problem. In particular, by committing to an active stabilization policy using public spending, policymakers influence expectations in such a way that national inflation rates and the terms of trade (relative to their natural level) become more stable. Indeed, a failure to commit fiscal policy leads to non-trivial welfare losses.

We investigate several variations on our benchmark. One is to have fiscal policy ex-

\footnotetext{
${ }^{1}$ For example, see the volume edited by Taylor (1999) or the Special Issue of Journal of Monetary Economics 43(3) (1999), for a number of recent contributions.

${ }^{2}$ Hence, we implicitly assume that monetary policy is coordinated because there is a common central bank that sets monetary policy for the entire union. Examples of papers that consider the desirability of monetary policy coordination in the context of recent open-economy models are Obstfeld and Rogoff (2001), Corsetti and Pesenti (2001a,b), Benigno and Benigno (2001), Clarida et al. (2002), Canzoneri et al. (2002) and Sutherland (2002).
} 
clusively directed at the efficient provision of public goods, so that it takes no part in macroeconomic stabilization. Restricting fiscal policy in this way leads to welfare losses that are equal to a permanent reduction in consumption of the order of $0.5-1$ percentage point when compared with the benchmark. Second, we consider cross-country differences in price rigidity. Here, we find that the optimal common monetary policy puts a more-than-proportionate emphasis on stabilizing the inflation rate of the country with the highest degree of price rigidity. As a result, the other country is characterized by more variable inflation and, therefore, its fiscal policy is more actively used. Finally, we vary the cross-country correlation of the supply shocks. Because it is the variance of the difference between the supply shocks of the two countries that determines the macroeconomic fluctuations, with perfectly correlated shocks, appropriate policy choices ensure that the equilibrium coincides with the efficient flexible-price equilibrium. When the shock correlation drops, welfare losses rise proportionately, whether or not fiscal policy can be used as an instrument for stabilization at the national level.

As the final step in our analysis we explore simple policy rules. Their advantage is that they are relatively simple to understand and transparent. As a result, it may be easier to commit to them than to the optimal policy. ${ }^{3}$ First, we explore rules that mimic the optimal monetary policy as closely as possible and have public spending respond to the terms of trade, thereby stabilizing national inflation. In particular, a terms-of-trade deterioration should lead to a contractionary fiscal policy. This combination of policy rules improves on the optimal policy under discretion. Nevertheless, it is beaten by the optimal commitment policy with a loss equivalent to a permanent consumption reduction in the order of 0.3 to 0.6 percentage points.

A standard monetary policy Taylor-rule, combined with rules in which public spending reacts to the output gap, also performs well in general and produces losses very close to those under the combination of rules described above. The optimal fiscal rules are countercyclical and for our baseline parameter combination a 1 percentage point increase in the output gap causes a fall in spending of somewhat more than 1 percentage point.

Obviously our analysis will be subject to a number of limitations, of which we mention only a few here: because of Ricardian equivalence, public debt plays no explicit role here; governments have recourse to lump-sum taxes/subsidies that are used to offset monopolistic distortions; and public spending contributes directly to individuals' utility. We view the present paper as an early step in combining monetary and fiscal policy in a New-Keynesian model of a monetary union and explore only the relaxation of the lastmentioned assumption. However, we realize that relaxing other assumptions may well affect the results in ways that would be worthwhile to investigate in further research.

The remainder of this paper is structured as follows. Section 2 presents the model. Section 3 derives the steady state, the flexible-price equilibrium, and the sticky-price

\footnotetext{
${ }^{3}$ Note our qualifier "may." Svensson (2001), for example, argues strongly against such instrument rules, and concludes that optimizing behavior implying targeting rules (essentially the first-order conditions resulting from the optimization) is more transparent.
} 
equilibrium conditional on the policy instruments. Section 4 discusses the setup of the policy analysis, while Section 5 presents and discusses the (numerical) results under the optimal policies and our rules. Finally, Section 6 concludes the main body of the paper.

\section{The model}

We extend the basic model developed by Benigno (2001) by introducing public spending as an instrument for stabilization and by introducing demand-side preference shocks. The presentation of the model and the notation closely parallels that of Benigno (2001).

\subsection{Utilities and private consumption}

There are two countries labeled $H$ (ome) and $F$ (oreign). These countries form a monetary union. The population of the union is a continuum of agents on the interval $[0,1]$. The population on the segment $[0, n)$ belongs to country $H$, while the population on $[n, 1]$ belongs to country $F$. In period $t$, the utility of the representative household $j$ living in country $i$ is given by

$$
U_{t}^{j}=\mathrm{E}_{t} \sum_{s=t}^{\infty} \beta^{s-t}\left[U\left(C_{s}^{j}, \epsilon_{s}^{i}\right)+V\left(G_{s}^{j}\right)-v\left(y_{s}^{j}, z_{s}^{i}\right)\right], \quad 0<\beta<1,
$$

where $C_{s}^{j}$ is consumption, $G_{s}^{j}$ is per-capita public spending, and $y_{s}^{j}$ is the amount of goods that household $j$ produces. The functions $U$ and $V$ are strictly increasing and strictly concave, and $v$ is increasing and strictly convex in $y_{s}^{j}$. Thus, households receive utility from consumption and public spending, but experience disutility from their work effort. Further, $\epsilon_{s}^{i}$ is a shock which affects the demand for consumption goods, and $z_{s}^{i}$ is a shock affecting disutility of work, which will throughout be interpreted as a supply (e.g., technology) shock. ${ }^{4}$ We assume that these shocks are perfectly observable by all the agents (households and policymakers - introduced below). For convenience, we also assume that the variances of $z_{s}^{H}$ and $z_{s}^{F}$ are equal.

The consumption index $C^{j}$ is defined as

$$
C^{j} \equiv \frac{\left(C_{H}^{j}\right)^{n}\left(C_{F}^{j}\right)^{1-n}}{n^{n}(1-n)^{1-n}}
$$

where $C_{H}^{j}$ and $C_{F}^{j}$ are the Dixit and Stiglitz (1977) indices of the sets of imperfectly substitutable goods produced in countries $H$ and $F$, respectively:

$$
C_{H}^{j} \equiv\left[\left(\frac{1}{n}\right)^{1 / \sigma} \int_{0}^{n} c^{j}(h)^{\frac{\sigma-1}{\sigma}} d h\right]^{\frac{\sigma}{\sigma-1}}, \quad C_{F}^{j} \equiv\left[\left(\frac{1}{1-n}\right)^{1 / \sigma} \int_{n}^{1} c^{j}(f)^{\frac{\sigma-1}{\sigma}} d f\right]^{\frac{\sigma}{\sigma-1}},
$$

\footnotetext{
${ }^{4}$ We could have introduced real money balances as an argument in (1). However, if it enters additively (as empirical evidence suggests — see Ireland, 2000, for the case of the U.S. and Andrés et al., 2001, for the case of EMU), money market equilibrium plays no role for the dynamics when the nominal interest rate is the monetary policy instrument. Therefore, we ignore money in the remainder.
} 
where $c^{j}(h)$ and $c^{j}(f)$ are $j$ 's consumption of Home- and Foreign-produced goods $h$ and $f$, respectively, and $\sigma>1$ is the elasticity of substitution across goods produced within a country.

The price index of country $i$ is given by $P^{i}=\left(P_{H}^{i}\right)^{n}\left(P_{F}^{i}\right)^{1-n}$ where

$$
P_{H}^{i}=\left[\left(\frac{1}{n}\right) \int_{0}^{n} p^{i}(h)^{1-\sigma} d h\right]^{\frac{1}{1-\sigma}}, \quad P_{F}^{i}=\left[\left(\frac{1}{1-n}\right) \int_{n}^{1} p^{i}(f)^{1-\sigma} d f\right]^{\frac{1}{1-\sigma}}
$$

and where $p^{i}(h)$ and $p^{i}(f)$ are the prices in country $i$ of the individual goods $h$ and $f$ produced in Home and Foreign, respectively. Because there are no trade barriers and the two countries share a common currency, the price of each good is the same in both countries. Combined with the fact that preferences are identical in the entire union, purchasing power parity holds. In the sequel, we will therefore drop the country superscript for prices. The terms of trade, $T$, is defined as the ratio of the price of a bundle of goods produced in country $F$ and a bundle of goods produced in country $H$. That is, $T \equiv P_{F} / P_{H}$.

The allocation of resources over the various consumption goods takes place in three steps. The intertemporal trade-off, analyzed below, determines $C^{j}$. Given $C^{j}$, the household selects $C_{H}^{j}$ and $C_{F}^{j}$ so as to minimize total expenditure $P C^{j}$ under restriction (2). Then, given $C_{H}^{j}$ and $C_{F}^{j}$, the household optimally allocates spending over the individual goods by minimizing $P_{H} C_{H}^{j}$ and $P_{F} C_{F}^{j}$ under restriction (3). The implied demands for individual good $h$, produced in country $H$, and individual good $f$, produced in country $F$, are, respectively,

$$
c^{j}(h)=\left(\frac{p(h)}{P_{H}}\right)^{-\sigma} T^{1-n} C^{j}, \quad c^{j}(f)=\left(\frac{p(f)}{P_{F}}\right)^{-\sigma} T^{-n} C^{j} .
$$

We assume that public spending is financed either by debt issuance or lump-sum taxation, so that Ricardian equivalence holds. Public spending in countries $H$ and $F$ is given by the following indices, respectively:

$$
G^{H}=\left[\frac{1}{n} \int_{0}^{n} g(h)^{\frac{\sigma-1}{\sigma}} d h\right]^{\frac{\sigma}{\sigma-1}}, \quad G^{F}=\left[\frac{1}{1-n} \int_{n}^{1} g(f)^{\frac{\sigma-1}{\sigma}} d f\right]^{\frac{\sigma}{\sigma-1}},
$$

where $g(h)$ and $g(f)$ are public spending on individual goods $h$ and $f$ produced in Home and Foreign, respectively. Hence, we assume that the national governments only purchase goods produced in their own country. While this is an extreme situation, fiscal policy remains effective at stabilizing the individual economies in the face of asymmetric disturbances as long as the public spending indices remain biased towards nationally produced goods. As will become evident below, government spending will be expansionary when prices are sticky. ${ }^{5}$ In this respect, we should emphasize that government spending in this

\footnotetext{
${ }^{5}$ If we were to relax the assumption that the government can levy lump-sum taxes, changes in the amount of public spending would lead to fluctuations in distortionary taxes, thereby affecting the supplyside of the economy and potentially diminishing the stimulating effect of an increase in government spending. However, this is beyond the scope of the present paper.
} 
model is associated with government purchases and not with government outlays on public wages. The latter are often thought to be contractionary. ${ }^{6}$

Minimization of $P_{H} G^{H}$ and $P_{F} G^{F}$ under restriction (5) yields the governments' demands for the individual goods $h$ and $f$ :

$$
g(h)=\left(\frac{p(h)}{P_{H}}\right)^{-\sigma} G^{H}, \quad g(f)=\left(\frac{p(f)}{P_{F}}\right)^{-\sigma} G^{F} .
$$

Hence, combining (4) and (6), the total demands for the goods $h$ and $f$ are

$$
y(h)=\left(\frac{p(h)}{P_{H}}\right)^{-\sigma}\left[T^{1-n} C^{W}+G^{H}\right], \quad y(f)=\left(\frac{p(f)}{P_{F}}\right)^{-\sigma}\left[T^{-n} C^{W}+G^{F}\right],
$$

where $C^{W} \equiv \int_{0}^{1} C^{j} d j$, is aggregate consumption in the union.

Following Benigno and Benigno (2001), we assume that financial markets are complete both at the domestic and at the international level. Furthermore, each individual's initial holding of any type of asset is zero. These assumptions imply perfect consumption risksharing within each country and equalization of the marginal utilities of consumption between countries:

$$
U_{C}\left(C_{t}^{H}, \epsilon_{t}^{H}\right)=U_{C}\left(C_{t}^{F}, \epsilon_{t}^{F}\right)
$$

Further, the Euler equations are

$$
U_{C}\left(C_{t}^{i}, \epsilon_{t}^{i}\right)=\left(1+R_{t}\right) \beta \mathrm{E}_{t}\left[U_{C}\left(C_{t+1}^{i}, \epsilon_{t+1}^{i}\right)\left(P_{t} / P_{t+1}\right)\right], \quad i=H, F
$$

where $R_{t}$ is the nominal interest rate on an internationally-traded nominal bond. This is taken to be the union central bank's policy instrument. Finally, using the appropriate aggregators, aggregate demand in both countries is found as

$$
Y^{H}=T^{1-n} C^{W}+G^{H}, \quad Y^{F}=T^{-n} C^{W}+G^{F} .
$$

\subsection{Firms}

Individual $j$ is the monopolist provider of good $j$. We use Calvo's (1983) approach to modelling price stickiness. In each period, there is a fixed probability $\left(1-\alpha^{i}\right)$ that producer $j$ who resides in $i$ can adjust his prices. This producer takes account of the fact that a change in the price of his product affects the demand for it. However, because he is infinitesimally small, he neglects any effects of his actions on aggregate variables. Hence, if individual $j$ has the "chance" to reset his price in period $t$, he chooses his price, denoted $p_{t}(j)$, to maximize

$$
\mathrm{E}_{t} \sum_{k=0}^{\infty}\left(\alpha^{i} \beta\right)^{k}\left[\lambda_{t+k}^{i}\left(1-\tau^{i}\right) p_{t}(j) y_{t, t+k}(j)-v\left(y_{t, t+k}(j), z_{t+k}^{i}\right)\right],
$$

\footnotetext{
${ }^{6}$ See Wynne (1996) and Finn (1998) for theoretical examples, and Alesina et al. (1999) for empirical evidence for the OECD countries. However, Fatás and Mihov (2001) cannot unambiguously confirm this finding for the U.S.
} 
where $y_{t, t+k}(j)$ is given by $(7), \lambda_{t+k}^{i} \equiv U_{C}\left(C_{t+k}^{i}, \epsilon_{t+k}^{i}\right) / P_{t+k}$ is the marginal utility of nominal income and $\tau^{i}$ is a proportional tax rate on nominal income. This yields:

$$
p_{t}(j)=\frac{\sigma}{(\sigma-1)\left(1-\tau^{i}\right)} \frac{\mathrm{E}_{t}\left[\sum_{k=0}^{\infty}\left(\alpha^{i} \beta\right)^{k} v_{y}\left(y_{t, t+k}(j), z_{t+k}^{i}\right) y_{t, t+k}(j)\right]}{\mathrm{E}_{t}\left[\sum_{k=0}^{\infty}\left(\alpha^{i} \beta\right)^{k} \lambda_{t+k}^{i} y_{t, t+k}(j)\right]} .
$$

Realizing that, in equilibrium, each producer in a given country in a given period will set the same price when given the chance to change its price, it is easy to show that

$$
\begin{aligned}
& P_{H, t}^{1-\sigma}=\alpha^{H} P_{H, t-1}^{1-\sigma}+\left(1-\alpha^{H}\right) p_{t}(h)^{1-\sigma}, \\
& P_{F, t}^{1-\sigma}=\alpha^{F} P_{F, t-1}^{1-\sigma}+\left(1-\alpha^{F}\right) p_{t}(f)^{1-\sigma} .
\end{aligned}
$$

\section{Equilibrium}

\subsection{Steady state and efficient flex-price equilibrium}

Under flexible prices, (11) is replaced by

$$
p_{t}(j)=\frac{\sigma}{(\sigma-1)\left(1-\tau^{i}\right)} \frac{v_{y}\left(y_{t, t}(j), z_{t}^{i}\right) y_{t, t}(j)}{\lambda_{t}^{i} y_{t, t}(j)} .
$$

Because each agent in a given country chooses the same price, we have that $p_{t}(j)=P_{H, t}$ for all $j$ living in Home, so that

$$
U_{C}\left(C_{t}^{H}, \epsilon_{t}^{H}\right)=\frac{\sigma}{(\sigma-1)\left(1-\tau^{H}\right)} T_{t}^{1-n} v_{y}\left(T_{t}^{1-n} C_{t}^{W}+G_{t}^{H}, z_{t}^{H}\right),
$$

and that $p_{t}(j)=P_{F, t}$ for all $j$ living in Foreign, so that

$$
U_{C}\left(C_{t}^{F}, \epsilon_{t}^{F}\right)=\frac{\sigma}{(\sigma-1)\left(1-\tau^{F}\right)} T_{t}^{-n} v_{y}\left(T_{t}^{-n} C_{t}^{W}+G_{t}^{F}, z_{t}^{F}\right) .
$$

In the sequel, we confine ourselves to equilibria in which the tax rates $\tau^{H}$ and $\tau^{F}$ are set so as to offset the distortion arising from monopolistic competition:

$$
\frac{\sigma}{(\sigma-1)\left(1-\tau^{H}\right)}=\frac{\sigma}{(\sigma-1)\left(1-\tau^{F}\right)}=1
$$

We assume that the steady state is characterized by zero inflation in both countries, and denote by an upper-bar the steady-state value of a variable. The steady-state values $\bar{C} \equiv \bar{C}^{H}=\bar{C}^{F}=\bar{C}^{W}$ and $\bar{T}$, conditional on $\bar{G}^{H}$ and $\bar{G}^{F}$, follow upon setting the shocks to zero in (15) and (16), with (17) imposed. Hence, they are implicitly defined by

$$
U_{C}(\bar{C}, 0)=\bar{T}^{1-n} v_{y}\left(\bar{T}^{1-n} \bar{C}+\bar{G}^{H}, 0\right)=\bar{T}^{n} v_{y}\left(\bar{T}^{-n} \bar{C}+\bar{G}^{F}, 0\right) .
$$

Assuming a symmetric steady state, it follows that $\bar{T}=1$. We obtain the steady state values $\bar{G}^{H}$ and $\bar{G}^{F}$ by setting the shocks to zero in (21) below:

$$
V_{G}\left(\bar{G}^{H}\right)=v_{y}\left(\bar{Y}^{H}, 0\right), \quad V_{G}\left(\bar{G}^{F}\right)=v_{y}\left(\bar{Y}^{F}, 0\right) .
$$


Finally, we obtain the steady-state nominal (=real) interest rate from (9) as $1+\bar{R}=1 / \beta$.

Before we continue, we introduce some notation. Following Benigno (2001), we denote with a superscript " $W$ " a world aggregate and with a superscript " $R$ " a relative variable. Hence, for a generic variable $X$, we define $X^{W} \equiv n X^{H}+(1-n) X^{F}$ and $X^{R} \equiv X^{F}-X^{H}$. Further, we denote by a tilde the flex-price log-deviation from the steady state, i.e., $\widetilde{X} \equiv$ $\ln (X / \bar{X})$.

For the flexible-price equilibrium that we consider, we assume that the fiscal authorities coordinate. Hence, they choose $G_{t}^{H}$ and $G_{t}^{F}$ to maximize

$$
\mathrm{E}_{t} \sum_{s=t}^{\infty} \beta^{s-t}\left\{\begin{array}{c}
n\left[U\left(C_{s}^{H}, \epsilon_{s}^{H}\right)+V\left(G_{s}^{H}\right)-v\left(Y_{s}^{H}, z_{s}^{H}\right)\right] \\
+(1-n)\left[U\left(C_{s}^{F}, \epsilon_{s}^{F}\right)+V\left(G_{s}^{F}\right)-v\left(Y_{s}^{F}, z_{s}^{F}\right)\right]
\end{array}\right\}
$$

again subject to (15) and (16), with (17) imposed. Because there are no distortions, this programme gives the highest possible weighted welfare level. Therefore, we term the resulting equilibrium the efficient flex-price equilibrium. The fiscal choice problem implies the following optimality conditions:

$$
V_{G}\left(G_{t}^{H}\right)=v_{y}\left(Y_{t}^{H}, z_{t}^{H}\right), \quad V_{G}\left(G_{t}^{F}\right)=v_{y}\left(Y_{t}^{F}, z_{t}^{F}\right)
$$

These conditions are derived in Appendix A, where we also derive the complete solution for the efficient flex-price equilibrium:

$$
\begin{gathered}
\widetilde{C}_{t}^{W}=\frac{\eta \rho_{g}}{\rho\left[\rho_{g}+\eta\left(1-\xi_{c}\right)\right]+\eta \xi_{c} \rho_{g}} S_{t}^{W}-\frac{\rho\left[\rho_{g}+\eta\left(1-\xi_{c}\right)\right]}{\rho\left[\rho_{g}+\eta\left(1-\xi_{c}\right)\right]+\eta \xi_{c} \rho_{g}} D_{t}^{W} \\
\widetilde{G}_{t}^{W}=\frac{\eta \rho}{\rho\left[\rho_{g}+\eta\left(1-\xi_{c}\right)\right]+\eta \xi_{c} \rho_{g}}\left(S_{t}^{W}+\xi_{c} D_{t}^{W}\right) \\
\widetilde{G}_{t}^{R}=\frac{\eta}{\rho_{g}\left(1+\eta \xi_{c}\right)+\eta\left(1-\xi_{c}\right)} S_{t}^{R} \\
\widetilde{T}_{t}=-\frac{\eta \rho_{g}}{\rho_{g}\left(1+\eta \xi_{c}\right)+\eta\left(1-\xi_{c}\right)} S_{t}^{R}
\end{gathered}
$$

where, $\rho \equiv-U_{C C}(\bar{C}, 0) \bar{C} / U_{C}(\bar{C}, 0), \rho_{g} \equiv-V_{G G}(\bar{G}) \bar{G} / V_{G}(\bar{G}), \xi_{c}$ is the steady-state consumption share of output, and $\eta \equiv v_{y y}\left(\bar{Y}^{H}, 0\right) \bar{Y}^{H} / v_{y}\left(\bar{Y}^{H}, 0\right)=v_{y y}\left(\bar{Y}^{F}, 0\right) \bar{Y}^{F} / v_{y}\left(\bar{Y}^{F}, 0\right)$, because $\bar{Y}^{H}=\bar{Y}^{F}$. Furthermore, we have defined $S_{t}^{i}(i=H, F)$ such that $v_{y z}\left(\bar{Y}^{i}, 0\right) z_{t}^{i}=$ $-\bar{Y}^{i} v_{y y}\left(\bar{Y}^{i}, 0\right) S_{t}^{i}$ and $D_{t}^{i}$ such that $U_{C \epsilon}(\bar{C}, 0) \epsilon_{t}^{i}=\bar{C} U_{C C}(\bar{C}, 0) D_{t}^{i}$. Hence, $S_{t}^{i}$ and $D_{t}^{i}$ are proportional to the supply and demand shocks, respectively. We will refer to the outcomes of the above variables in the efficient flex-price equilibrium as the (stochastic) natural rates.

As we will see below, fluctuations in the natural terms of trade will be the source of the policy trade-offs in the model under sticky prices. As (25) shows, the natural 
terms of trade fluctuate when non-identical supply shocks hit the two economies. We can explain this as follows. Because of perfect consumption risk sharing, the marginal utilities of consumption are equated across countries. Moreover, the marginal utilities of consumption are equated to the implied marginal disutility of additional production effort [see (15) and (16)]. A positive supply shock in Home relative to Foreign reduces Home's effort needed to produce a given amount of output. Production of Home needs to increase relative to the production of Foreign to ensure that the disutilities of effort are equated again. To restore the equilibrium, the price of Home goods relative to Foreign goods must decrease, i.e., $\widetilde{T}_{t}$ should increase. Any demand disturbances, however, have no effect on the natural terms of trade. They merely alter the marginal utilities of consumption, but by the same amount in both countries. Therefore, production effort changes by the same amount in both countries, leaving any relative price change superfluous.

Finally, assuming that the inflation rate in the flex-price equilibrium is zero, we derive the natural rate of the nominal interest rate as

$$
\widetilde{R}_{t}=\rho \mathrm{E}_{t}\left[\left(\widetilde{C}_{t+1}^{W}-\widetilde{C}_{t}^{W}\right)+\left(D_{t+1}^{W}-D_{t}^{W}\right)\right]
$$

\subsection{Equilibrium dynamics under sticky prices}

Under sticky prices, the aggregate demand block is given by (8), (9) and (10), while the aggregate supply block is (11), (12), (13). Applying the appropriate linearizations (see Appendix B), together with the initial conditions, we end up with the following dynamic system, where a hat indicates the log-deviation from the steady state when prices are sticky, i.e., $\widehat{X} \equiv \ln (X / \bar{X})$ :

$$
\begin{gathered}
\mathrm{E}_{t}\left(\widehat{C}_{t+1}^{W}-\widetilde{C}_{t+1}^{W}\right)=\left(\widehat{C}_{t}^{W}-\widetilde{C}_{t}^{W}\right)+\rho^{-1}\left[\left(\widehat{R}_{t}-\widetilde{R}_{t}\right)-\mathrm{E}_{t}\left(\pi_{t+1}^{W}\right)\right], \\
\widehat{Y}_{H, t}=\xi_{c}\left[(1-n) \widehat{T}_{t}+\widehat{C}_{t}^{W}\right]+\left(1-\xi_{c}\right) \widehat{G}_{t}^{H}, \\
\widehat{Y}_{F, t}=\xi_{c}\left[-n \widehat{T}_{t}+\widehat{C}_{t}^{W}\right]+\left(1-\xi_{c}\right) \widehat{G}_{t}^{F}, \\
\pi_{t}^{H}=\quad \beta \mathrm{E}_{t} \pi_{t+1}^{H}+k^{H}\left(1+\eta \xi_{c}\right)(1-n)\left(\widehat{T}_{t}-\widetilde{T}_{t}\right)+k^{H}\left(\rho+\eta \xi_{c}\right)\left(\widehat{C}_{t}^{W}-\widetilde{C}_{t}^{W}\right) \\
+k^{H} \eta\left(1-\xi_{c}\right)\left(\widehat{G}_{t}^{H}-\widetilde{G}_{t}^{H}\right), \\
\pi_{t}^{F}=\quad \beta \mathrm{E}_{t} \pi_{t+1}^{F}-k^{F}\left(1+\eta \xi_{c}\right) n\left(\widehat{T}_{t}-\widetilde{T}_{t}\right)+k^{F}\left(\rho+\eta \xi_{c}\right)\left(\widehat{C}_{t}^{W}-\widetilde{C}_{t}^{W}\right) \\
+k^{F} \eta\left(1-\xi_{c}\right)\left(\widehat{G}_{t}^{F}-\widetilde{G}_{t}^{F}\right), \\
\widehat{T}_{t}=\widehat{T}_{t-1}+\pi_{t}^{F}-\pi_{t}^{H},
\end{gathered}
$$

where we have made use of the fact that, upon log-linearizing (8) under both flexible and sticky prices, we obtain $\widehat{C}_{t}^{W}-\widetilde{C}_{t}^{W}=\widehat{C}_{t}^{H}-\widetilde{C}_{t}^{H}=\widehat{C}_{t}^{F}-\widetilde{C}_{t}^{F}$, and where,

$$
k^{H} \equiv \frac{\left(1-\alpha^{H} \beta\right)\left(1-\alpha^{H}\right)}{\alpha^{H}(1+\eta \sigma)}, \quad k^{F} \equiv \frac{\left(1-\alpha^{F} \beta\right)\left(1-\alpha^{F}\right)}{\alpha^{F}(1+\eta \sigma)} .
$$


In the following, the gap of a variable (including inflation) is defined as the difference between its sticky-price and its flex-price solution or natural rate. Equation (27) is the consumption Euler equation expressed in terms of the world consumption gap and the world real interest rate gap. Equations (28) and (29) are the log-linearized counterparts of (10). Equation (30) is the Home inflation adjustment equation, i.e., the "Phillips curve." Inflation depends positively on expected future inflation as agents setting prices in period $t$ know there is a risk that they cannot change their prices in period $t+1$. Hence, to protect discounted real income, expected future aggregate prices are crucial for price setting. A positive terms-of-trade gap has inflationary implications because demand is switched towards Home goods, and because Home agents' marginal utility of nominal income drops. Both effects will be met by price increases. Moreover, a positive consumption gap and government spending gap are inflationary due to their implied demand pressure. Equation (31) is the analogous foreign inflation adjustment equation. Note that by using (28) and (29), and their efficient flex-price counterparts, we can express these inflation adjustment equations in terms of output and terms-of-trade (and public spending) gaps. As such they resemble the open-economy counterparts of what Roberts (1995) labels the "New Keynesian" Phillips curves. ${ }^{7}$ Finally, equation (32) is the definition of the terms of trade expressed through the inflation differential. In sum, equations (27), (28), (29), (30), (31), (32), will for given paths of $\widehat{R}_{t}, \widehat{G}_{t}^{H}$ and $\widehat{G}_{t}^{F}$, and for an initial $\widehat{T}_{t-1}$, provide the solutions for the endogenous variables $\widehat{C}_{t}^{W}, \widehat{Y}_{H, t}, \widehat{Y}_{F, t}, \pi_{t}^{H}, \pi_{t}^{F}$ and $\widehat{T}_{t}$.

Before considering our monetary-fiscal policy experiments, it is appropriate to establish under what circumstances a replication of the efficient flex-price equilibrium is feasible in the model.

For illustrative purposes, we first discuss the special case in which public spending does not affect individuals' utility in at least one of the countries. In that case (22)-(25) no longer hold, as these have been derived under the assumption that the fiscal authorities maximize (20) over both $G_{t}^{H}$ and $G_{t}^{F}$. The system (27)-(32) remains valid because we derived it solely from the private sector's first-order conditions. One has:

Proposition 1 Suppose that public spending does not affect individuals' utility in at least one of the countries. Then, the appropriate combination of monetary and fiscal policies closes all the gaps.

To explain this result, observe that the monetary authority closes the consumption gap by (committing to) setting (for all $t) \widehat{R}_{t}=\widetilde{R}_{t}$. Next, if under flexible prices the fiscal authorities set $\widetilde{G}_{t}^{R}=S_{t}^{R} /\left(1-\xi_{c}\right)$, then by (45) in Appendix A, $\widetilde{T}_{t}=0$. To be specific,

\footnotetext{
${ }^{7}$ Empirical support for the depicted forward-looking behavior in price setting can be found in Galí and Gertler (1999) and Sbordone (2002) for the U.S. and in Galí et al. (2001) for the Euroland. Note that these studies use real marginal costs instead of the output gap as the driving variable. Recently, however, Neiss and Nelson (2002) have provided a theoretical and empirical reconciliation of marginal-cost based and output-gap based inflation equations. It should be observed that the empirical results of Coenen and Wieland (2000) for Euroland are more supportive of Taylor-style contracts than of Calvo-style contracts.
} 
suppose that only the Home consumers derive utility from public spending. Then, $\widetilde{G}_{t}^{H}$ follows from maximizing (20), with the term $V\left(G_{t}^{F}\right)$ dropped, over $G_{t}^{H}$, subject to (15), (16) and (17). The solutions for $\widetilde{G}_{t}^{H}$ and $\widetilde{G}_{t}^{R}$ then determine $\widetilde{G}_{t}^{F} \cdot{ }^{8}$ As a final step, from (30) and (31), with $\widehat{G}_{t}^{H}-\widetilde{G}_{t}^{H}=-\frac{\left(1+\eta \xi_{c}\right)(1-n)}{\eta\left(1-\xi_{c}\right)}\left(\widehat{T}_{t}-\widetilde{T}_{t}\right)$ and $\widehat{G}_{t}^{F}-\widetilde{G}_{t}^{F}=\frac{\left(1+\eta \xi_{c}\right) n}{\eta\left(1-\xi_{c}\right)}\left(\widehat{T}_{t}-\widetilde{T}_{t}\right)$, national producer inflation rates are zero. Hence, $\widehat{T}_{t}=\widetilde{T}_{t}$, so that in equilibrium all gaps are closed. The intuition is that when foreign public spending is "pure waste," it can be adjusted to eliminate any fluctuations in the natural rate of the terms of trade. Home public spending can then be set at its efficient level, while monetary policy can stabilize inflation rates perfectly by closing the consumption gap. ${ }^{9}$

For the remainder of the paper, we return to the case in which public spending enters the utility of all individuals. First, we consider two other special cases that produce the efficient flex-price equilibrium. One arises when at least one of the economies is characterized by full price flexibility. It is analogous to what Aoki (2002) obtains for a closed-economy, two-sector model. Formally, we have:

Proposition 2 Suppose that at least one of the economies is characterized by fully flexible prices $\left(\alpha^{H}=0\right.$ or $\left.\alpha^{F}=0\right)$. Then, the appropriate combination of monetary and fiscal policies closes all the gaps.

To see this, suppose that $\alpha^{F}=0$. Hence, by (31),

$$
\widehat{T}_{t}-\widetilde{T}_{t}=\frac{\rho+\eta \xi_{c}}{n\left(1+\eta \xi_{c}\right)}\left(\widehat{C}_{t}^{W}-\widetilde{C}_{t}^{W}\right)+\frac{\eta\left(1-\xi_{c}\right)}{n\left(1+\eta \xi_{c}\right)}\left(\widehat{G}_{t}^{F}-\widetilde{G}_{t}^{F}\right)
$$

We can substitute this expression into (30), to get rid of the terms-of-trade gap. The Home Phillips curve now depends on the consumption gap and the two government spending gaps. If the authorities (commit to) setting (for all $t$ ) $\widehat{R}_{t}=\widetilde{R}_{t}, \widehat{G}_{t}^{H}=\widetilde{G}_{t}^{H}$ and $\widehat{G}_{t}^{F}=\widetilde{G}_{t}^{F}$, all gaps are closed. In other words, even though the natural terms of trade fluctuate, the price flexibility in one country serves as a stabilizing device, which assures that the available three policy instruments become sufficient for attaining efficiency.

We can also establish efficiency when the supply shocks fulfill a specific restriction. From the Phillips curves (30) and (31), the following proposition is immediate:

Proposition 3 Let $\widehat{T}_{-1}=0$ and suppose that the supply shocks are perfectly correlated. Then, the appropriate combination of monetary and fiscal policies closes all the gaps.

By (committing to) setting (for all $t) \widehat{R}_{t}=\widetilde{R}_{t}, \widehat{G}_{t}^{H}=\widetilde{G}_{t}^{H}$ and $\widehat{G}_{t}^{F}=\widetilde{G}_{t}^{F}$, and observing that $\widetilde{T}_{t}=0$ with perfectly correlated supply shocks, we obtain an equilibrium in which the consumption gap is closed and the national producer inflation rates are zero. This equilibrium is validated by observing that $\widehat{T}_{t}=0$ and, hence, that $\widehat{T}_{t}=\widetilde{T}_{t}$. This result

\footnotetext{
${ }^{8}$ The Additional Appendix (available upon request) derives $\widetilde{C}_{t}^{W}$ and $\widetilde{G}_{t}^{H}$ for this case.

${ }^{9}$ When for both countries public spending does not enter the individuals' utility, fixing $\widetilde{G}_{t}^{H}$ at some value determines $\widetilde{G}_{t}^{F}$ via $\widetilde{G}_{t}^{R}=S_{t}^{R} /\left(1-\xi_{c}\right)$.
} 
holds irrespective of potential differences in the degree of price stickiness between the countries. Hence, in this special case policy can be designed so as to replicate the efficient flex-price equilibrium. The reason is that with three policy instruments and no fluctuations in the natural terms of trade, no policy trade-offs arise.

Now, suppose that both economies feature some price rigidity, and that the supply shocks are imperfectly correlated. Is it still always possible to attain the efficient flex-price equilibrium through appropriate instrument settings? The answer is no. We formally state this result in the following proposition:

Proposition 4 Assume that $\widehat{T}_{t-1}=0$ and that $\widetilde{T}_{t} \neq 0$ (because of an asymmetric supply shock). Then, setting fiscal policy such that $\widehat{G}_{s}^{H}=\widetilde{G}_{s}^{H}$ and $\widehat{G}_{s}^{F}=\widetilde{G}_{s}^{F}$ and monetary policy such that $\widehat{C}_{s}^{W}=\widetilde{C}_{s}^{W}$, for all $s \geq t$, and imposing that $\widehat{T}_{s}=\widetilde{T}_{s}$ for all $s \geq t+1$, implies that $\widehat{T}_{t} \neq \widetilde{T}_{t}$.

Proof: let $\widehat{T}_{t-1}=0$ and $\widetilde{T}_{t} \neq 0$. Suppose that, with $\widehat{G}_{s}^{H}=\widetilde{G}_{s}^{H}, \widehat{G}_{s}^{F}=\widetilde{G}_{s}^{F}$ and $\widehat{C}_{s}^{W}=\widetilde{C}_{s}^{W}$, for all $s \geq t$, and $\widehat{T}_{s}=\widetilde{T}_{s}$ for all $s \geq t+1$, we had that $\widehat{T}_{t}=\widetilde{T}_{t}$. Then, $\pi_{t}^{H}=\pi_{t}^{F}=0$. Hence, $\widehat{T}_{t}=0 \neq \widetilde{T}_{t}$. Contradiction.

In other words, it is generally not possible to close all gaps at all times when supply shocks are imperfectly correlated. The reason is that the associated fluctuations in $\widetilde{T}_{t}$ create a policy dilemma. On the one hand, when fiscal policies are aimed at securing efficient public spending levels, the common monetary policy cannot induce the required relative price change without destabilizing national inflation rates. In fact, as we discuss in more detail in Section 5, with equal nominal rigidities (i.e., $\alpha^{H}=\alpha^{F}$ ), the terms of trade are completely insulated from monetary policy (cf. Benigno, 2001). On the other hand, when fiscal policies are aimed at inducing the needed relative price change, public spending is no longer efficient. Hence, only in the special cases described by Propositions 1-3, policy trade-offs will vanish. Note that Proposition 4 confirms Benigno's (2001) finding for the case in which fiscal policy is absent. It thus follows that introducing fiscal policy cannot provide sufficient flexibility for attaining efficiency as can independent currencies in his model. Nevertheless, as we shall see below, fiscal policy may still be helpful in providing macroeconomic stabilization.

\section{Setup of the policy analysis}

\subsection{The objective function}

There is an increasing pressure on the countries in the European Union to intensify the coordination of macroeconomic policies. Of course, by now there is a common monetary policy. However, the quest for common policymaking in other areas, such as labor market policies and social policies is becoming louder too. As regards to fiscal policy, some steps have already been taken with the adoption of the Stability and Growth Pact. Sometimes the suggestion is made that it is necessary to set up a political counterweight to the ECB. 
France, in particular, has repeatedly expressed the need for intensified fiscal coordination and a potential vehicle for such coordination would be to endow the Eurogroup (the Finance Ministers of the Euro area) with (more) formal powers. As we are interested in the coordination of fiscal policies, the relevant objective function for our purpose is the union-level supranational loss function given by:

$$
L=\sum_{t=1}^{\infty} \beta^{t-1} \mathrm{E}_{1}\left[L_{t}\right],
$$

where

$$
\begin{aligned}
L_{t}= & \lambda_{C}\left(\widehat{C}_{t}^{W}-\widetilde{C}_{t}^{W}\right)^{2}+\lambda_{T}\left(\widehat{T}_{t}-\widetilde{T}_{t}\right)^{2}+\lambda_{G H}\left(\widehat{G}_{t}^{H}-\widetilde{G}_{t}^{H}\right)^{2} \\
& +\lambda_{G F}\left(\widehat{G}_{t}^{F}-\widetilde{G}_{t}^{F}\right)^{2}+\lambda_{\pi^{H}}\left(\pi_{t}^{H}\right)^{2}+\lambda_{\pi^{F}}\left(\pi_{t}^{F}\right)^{2},
\end{aligned}
$$

with all weights non-negative. That is, any deviation of endogenous variables from their efficient flex-price level constitutes a welfare loss. While we postulate this loss function, we motivate it by the fact that it generalizes the loss function that Benigno (2001) derives formally for the case in which fiscal policy as an instrument for macroeconomic stabilization is absent. In particular, if $\lambda_{G H}=\lambda_{G F}=0$, this loss function would have the same format as Benigno's (2001) loss function, which is (minus) a second-order Taylor approximation to a utilitarian welfare function which weighs equally the utility of each individual in the union and where the parameters in (34) are functions of the "deep" parameters of the model (see below).

\subsection{The policies}

We consider several types of policies. One type concerns the optimal policies. Here, we distinguish between commitment and discretion, as there will generally be gains from commitment as mentioned in the Introduction. The technical details for the computation of the optimal policies are available upon request from the authors. ${ }^{10}$ As one of our main questions concerns the contribution of fiscal policy to the stabilization of shocks, within the set of optimal policies, we consider "full" optimization over the complete vector of policy instruments $\left(\begin{array}{lll}\widehat{R}_{t} & \widehat{G}_{t}^{H} & \widehat{G}_{t}^{F}\end{array}\right)^{\prime}$ and restricted optimization over monetary policy only, with fiscal policy restricted to be passive in the sense that $\widehat{G}_{t}^{H}=\widetilde{G}_{t}^{H}$ and $\widehat{G}_{t}^{F}=\widetilde{G}_{t}^{F}$. That is, fiscal policymaking is exclusively concerned with securing the efficient provision of public goods, and takes no part in stabilizing other macroeconomic variables.

We will also explore various policy rules. Although such rules are generally suboptimal relative to the optimal commitment policy, the latter is often merely regarded as a benchmark. In reality it would be hard to achieve, because the policymakers would have an incentive to deviate from the optimal plan. Although policy rules generally also require

\footnotetext{
${ }^{10}$ The policies and associated losses are computed numerically using the solution algorithms described by, e.g., Backus and Driffill (1986), Svensson (1994) and Söderlind (1999).
} 
commitment, the incentive to deviate from the rule would be weaker if it is transparent and simple, so that deviations from the rule can easily be detected and punished, either through a loss of confidence from the public/financial markets or by other policymakers. For example, the latter might exclude the "misbehaving" policymaker from their joint decision-making process (see, however, the caveat on policy rules versus fully optimal policymaking in Footnote 3).

The monetary and fiscal policy rules that we will consider all fall within the rather general class of rules given by

$$
\begin{aligned}
\widehat{R}_{t}-\widetilde{R}_{t}= & \left(b_{H} \pi_{t}^{H}+b_{F} \pi_{t}^{F}\right)+b_{C}\left(\widehat{C}_{t}^{W}-\widetilde{C}_{t}^{W}\right) \\
& +b_{T}\left(\widehat{T}_{t}-\widetilde{T}_{t}\right)+\left[d_{H} \mathrm{E}_{t}\left(\pi_{t+1}^{H}\right)+d_{F} \mathrm{E}_{t}\left(\pi_{t+1}^{F}\right)\right], \\
\widehat{G}_{t}^{H}-\widetilde{G}_{t}^{H}= & -g_{C H}\left(\widehat{C}_{t}^{W}-\widetilde{C}_{t}^{W}\right)-g_{T H}\left(\widehat{T}_{t}-\widetilde{T}_{t}\right), \\
\widehat{G}_{t}^{F}-\widetilde{G}_{t}^{F}= & -g_{C F}\left(\widehat{C}_{t}^{W}-\widetilde{C}_{t}^{W}\right)+g_{T F}\left(\widehat{T}_{t}-\widetilde{T}_{t}\right),
\end{aligned}
$$

which, for example, allow for the possibility to contract monetary policy when inflation or the consumption gap increases and to contract fiscal policy when the consumption gap increases or the terms-of-trade gap deteriorates. We will not optimize the combination (35) and (36) over all parameters. This would require an immense amount of computing time. More importantly, this would in some instances lead to coefficients of infinity (as we will explain below), which essentially makes no sense. Therefore, we consider specializations of the combination of rules (35) and (36), where in some cases we impose constraints on the coefficients of these rules.

\subsection{The benchmark parameter combination}

We largely follow Benigno (2001) in our choice of the benchmark parameter combination. The calibration is based on the assumption that each period corresponds to a quarter of a year. Benigno calibrates his model to the EMU situation and divides the area into two groups, one corresponding to relatively low nominal wage rigidity and the other corresponding to relatively high wage rigidity. Both groups have a weight of approximately $50 \%$ in Euro-area GDP, so that $n=0.5$. We set $\beta=0.99$, which implies a steady-state real rate of return of $1 \%$ on a quarterly basis. Parameter $\sigma$, capturing the degree of monopolistic competition, is set such that it is consistent with a steady-state mark up of prices over marginal costs of $15 \%$. Hence, we set $\sigma=7.66$. The benchmark values for $\alpha^{H}$ and $\alpha^{F}$ are selected so as to produce an average duration of a price contract of 1 year, so that $\alpha^{H}=\alpha^{F}=0.75$. We deviate from Benigno (2001) in our assumptions about the coefficient of relative risk aversion (RRA) for private consumption and the elasticity of the labor supply. Regarding the former, we assume that $\rho=2.5 .{ }^{11}$ We set the RRA coefficient

\footnotetext{
${ }^{11}$ For example, see Beetsma and Schotman (2001) and the references therein.
} 
for government spending, $\rho_{g}$, also at 2.5. Further, we set the elasticity of the labor supply at 0.1 , implying $\eta=10$. Finally, based on 0.6 and 0.2 being reasonable approximations for the private and government consumption shares of output in reality, we assume that $\xi_{c}=0.75$, so that private consumption is three times as large as government consumption.

The next step in the choice of the benchmark parameter values concerns the choice of the loss function parameters. Here, we make use of the expressions that Benigno (2001) - in the absence of endogenous government spending — derives for these parameters as functions of the "deep" model parameters. This yields the following expressions (up to an irrelevant proportionality factor):

$$
\begin{aligned}
\lambda_{C} & =\frac{(\rho+\eta) / \sigma}{n / k^{H}+(1-n) / k^{F}}, \quad \lambda_{T}=\frac{n(1-n)(1+\eta) / \sigma}{n / k^{H}+(1-n) / k^{F}}, \\
\lambda_{\pi^{H}} & =\frac{n / k^{H}}{n / k^{H}+(1-n) / k^{F}},
\end{aligned}
$$

We link the weight on public spending to its relative weight in output. Therefore, in the benchmark, we set $\lambda_{G}=\lambda_{C}\left[\left(1-\xi_{c}\right) / \xi_{c}\right]$.

The final step involves the choices about the shocks. We assume that the shocks follow $A R(1)$ processes:

$$
\begin{aligned}
S_{t}^{i} & =0.97 S_{t-1}^{i}+\mu_{S, t}^{i}, \quad i=H, F \\
D_{t}^{i} & =0.30 D_{t-1}^{i}+\mu_{D, t}^{i}, \quad i=H, F,
\end{aligned}
$$

where the $\mu_{D, t}^{i}$ and $\mu_{S, t}^{i}$ are white-noise innovations. We notice that the chosen degree of autocorrelation is higher for the supply shocks. This seems reasonable as we assume that supply shocks represent technology shocks. We set the standard deviation of the innovations in the process for the demand shock at $2.5 \%$, while the corresponding one for the supply shocks is $0.7 \%$. This provides a reasonable unconditional standard deviation of the supply shocks, and is in line with the standard assumptions of the real-businessliterature (e.g., see Cooley and Prescott, 1995). We may already note that the particular process chosen for the demand shock plays no role (see below). The baseline parameter combination assumes that the correlation between $\mu_{S, t}^{H}$ and $\mu_{S, t}^{F}$ is zero.

In the sequel, we consider a number of variations on the baseline parameter combination. We allow for asymmetries in the degree of price rigidity. In particular, we consider the case in which $\alpha^{H}=0.5$ and $\alpha^{F}=0.75$. The estimates in Galí et al. (2001) of $\alpha$ for Euroland range from 0.67 to 0.81 , while for the U.S. they range from 0.56 to 0.60 . Hence, the degree of asymmetry that we consider seems to be at the higher end. The benefit is that the range of variation in our parameter settings is more likely to cover the actual variation in rigidity in reality. We also vary the degree of (contemporaneous) correlation of the supply shocks and the elasticity of the labor supply. Finally, given our ignorance about the precise weight to be attached to public spending gaps in the loss function, we explore the robustness of the results for variations in this weight. 


\section{Discussion of the (numerical) results}

Before we turn to the results of the numerical analysis, we narrow down the set of possible parameters combinations that we need to investigate. In particular, we can exclude demand shocks from the analysis, as the following proposition shows:

Proposition 5 The demand shocks are irrelevant for the gaps of the optimal policies and the optimal rules. They are also irrelevant for the equilibrium welfare losses associated with the optimal policies and the optimal rules.

Even though the demand shocks affect the efficient flex-price equilibrium and thereby also the deviations of variables under sticky prices from their steady state values, the gaps of all the variables are unaffected by the demand shocks. For the optimal policies one can immediately see this result, if one realizes that the system (34), (27), (30), (31) and (32), with the latter rewritten as

$$
\widehat{T}_{t}-\widetilde{T}_{t}=\widehat{T}_{t-1}-\widetilde{T}_{t-1}+\pi_{t}^{F}-\pi_{t}^{H}-\left(\widetilde{T}_{t}-\widetilde{T}_{t-1}\right),
$$

is exhaustively expressed as a set of relations among gaps of variables and $\widetilde{T}_{t}-\widetilde{T}_{t-1}$. We can relabel all the gaps as, say, $Z_{1 t}, Z_{2 t}, \ldots$ Then, observing by $(25)$ that $\widetilde{T}_{t}-\widetilde{T}_{t-1}$ only depends on the (current and one-period lagged) relative supply shock, we are left with a system without demand shocks. This reasoning also once again explains why supply shocks in general do matter here. As regards to the irrelevance of the demand shocks in the case of our rules, we observe that the combination of rules (35) and (36) is exhaustively expressed in terms of gaps and national inflation rates, so that complementing the system (34), (27), (30), (31) and (32) by these rules yields again a system in gaps and the relative supply shock. Reiterating the "relabelling trick," we thus have a system without demand shocks.

We have assumed that all shocks and, thus, also the natural levels of variables are observable. Hence, when conducting optimal policies or implementing a rule, policymakers respond to the true natural rates. However, in practice, shocks are usually only imperfectly observable. As a result, natural levels can at most be imprecisely computed and their computation will generally affect the outcomes under optimal policies or under rules. Hence, given the imprecise knowledge about the natural levels of variables, practical policymaking is often based on deviations of variables, such as output, from a trend. Apart from problems with the observation of shocks, in practice there is also uncertainty about the correct macroeconomic model. This translates as an additional source of uncertainty into the computation of the natural levels of variables. Therefore, when assessing the performance of the policies to be investigated below we have to bear in mind these qualifications. Although beyond the scope of the present paper, it would be useful in further research to explore policy rules that are robust against the abovementioned concerns. 


\subsection{The optimal policies}

In this section we explore optimal policies. Appendix $\mathrm{C}$ characterizes formally the solution, but we stick to intuitive explanations here. We start with the benchmark case of full optimization over all three policy instruments under commitment and under the assumption that both countries are characterized by equal rigidities (i.e., $\alpha^{H}=\alpha^{F}$ and, thus, $k^{H}=k^{F} \equiv k$ ), that they are equally large (i.e., $n=\frac{1}{2}$ ) and that the supply shocks are uncorrelated. Because rigidities are equal, we can separate the model into two parts. Taking a weighted average of (30) and (31), we obtain the "world" Phillips curve

$$
\pi_{t}^{W}=\beta \mathrm{E}_{t} \pi_{t+1}^{W}+k\left[\left(\rho+\eta \xi_{c}\right)\left(\widehat{C}_{t}^{W}-\widetilde{C}_{t}^{W}\right)+\eta\left(1-\xi_{c}\right)\left(\widehat{G}_{t}^{W}-\widetilde{G}_{t}^{W}\right)\right]
$$

while subtracting (30) from (31), and using (32), yields:

$$
\widehat{T}_{t}-\widehat{T}_{t-1}=\beta \mathrm{E}_{t}\left(\widehat{T}_{t+1}-\widehat{T}_{t}\right)-k\left(1+\eta \xi_{c}\right)\left(\widehat{T}_{t}-\widetilde{T}_{t}\right)+k \eta\left(1-\xi_{c}\right)\left(\widehat{G}_{t}^{R}-\widetilde{G}_{t}^{R}\right),
$$

which shows that the terms of trade are completely insulated from monetary policy in this case, but not from fiscal policy. The combination of optimal policies is as follows. The monetary authority commits to setting the interest rate at the natural rate, which closes consumption gap and produces zero world inflation at all dates (because $\widehat{G}_{t}^{W}=\widetilde{G}_{t}^{W}$, as we explain below). However, in the present situation not all gaps can be closed, as Proposition 4 already showed, because zero world inflation hides opposite movements in local inflation rates, which prevent the terms of trade from always attaining its natural level. Public spending under the optimal plan is used to reduce the terms-of-trade gap, thereby dampening its effects on local inflation. When the terms-of-trade gap is positive (say), causing upward pressure on Home inflation, Home fiscal policy should be contractionary, and vice versa for the other country. In this symmetric case, the public spending gaps are equally large in absolute value, so that they offset each other in (38). (Appendix C shows this formally.)

We shall now explore a number of variations on the benchmark case. First, we investigate the benefits from commitment by computing the solution when policies are conducted under discretion. When the economies feature an equal degree of price rigidity, the commitment problem arises exclusively in fiscal policy, as there are no trade-offs in monetary policy, as we explained above. However, the fiscal authorities can gain if they commit to more aggressive and persistent policy responses towards shocks [the inertial nature of spending under commitment is seen formally in Appendix C, equations (53) and (54)]. This will affect inflation expectations, and thus help to stabilize current inflation. ${ }^{12}$ As a result, the terms-of-trade gap will become more stable. Although these gains come at the cost of more variable public spending, they dominate this cost. Hence, the discretionary scenario where fiscal policy is less active and persistent towards stabilizing shocks is welfare inferior, as the inflation/spending trade-off is worse since inflation expectations are

\footnotetext{
${ }^{12}$ This is analogous to the optimality of committing to an inertial monetary policy in a closed economy when shocks induce monetary policy trade-offs; cf. Woodford (1999a).
} 
not affected as strongly as under commitment. We present the losses for the two cases in Table 1, in the columns $L^{c}$ and $L^{d}$, respectively. However, to assess the welfare gains from commitment in "real world terms," we compute the permanent (and constant) percentage change in the consumption gap that would produce a given difference in losses. Call this percentage change $c$. We thus solve:

$$
\frac{\lambda_{C}}{1-\beta}\left(\frac{c}{100}\right)^{2}=L^{i}-L^{c}
$$

where $L^{c}$ is the loss under commitment with full optimization, and $L^{i}$ is the loss under the regime (in this case, full optimization under discretion) that we want to compare with $L^{c}$ in terms of "consumption equivalents". We report the figures in column $D$ of Table 2 and observe that the benefit from commitment is non-trivial, as it is equivalent to a permanent consumption gain of more than $0.5 \%$ for the benchmark case.

The purpose of the next variation is to explore the gains from using public spending for macroeconomic stabilization. To this end, we restrict fiscal policy to be passive (i.e., $\widehat{G}_{t}^{H}=\widetilde{G}_{t}^{H}$ and $\widehat{G}_{t}^{F}=\widetilde{G}_{t}^{F}$ ), so that it is only occupied with the efficient provision of public spending. The column $L^{c p}$ in Table 1 reports the losses, while column $C P$ in Table 2 expresses the loss relative to the case of full optimization with commitment in terms of permanent consumption losses. Hence, the benefit from using public spending for stabilization amounts to a permanent consumption gain of over $0.6 \%$ for the benchmark case. This figure may give an indication of the potential costs of the Stability and Growth Pact when its deficit upperbound is reached and it is no longer possible to stimulate the economy with a fiscal expansion. Note that because monetary policy does not suffer from a credibility problem in the benchmark, a passive fiscal policy leads to equal losses under commitment and discretion (see Table 1, with the loss under discretion in column $L^{d p}$ ).

The third variation on the benchmark case allows for asymmetry in price rigidity between the countries. Now, monetary policy is subject to a stabilization trade-off and commitment of monetary policy does yield welfare gains. ${ }^{13}$ The reason is that monetary policy now not only affects world variables, but also the terms of trade. Hence, monetary policy will no longer be exclusively focussed on stabilizing world inflation, but also on reducing movements in national inflation and the terms-of-trade gap. More specifically, if Foreign prices are relatively more sticky, the optimal policy setting allows Home inflation to be more variable than Foreign inflation. With Foreign prices being more sticky, it is optimal to direct monetary policy at trying to keep Foreign inflation closer to zero, so that losses resulting from persistent relative price differences within Foreign are reduced. This is analogous to Benigno's (2001) result that under a strict inflation targeting rule, the highest relative weight should be attached to the inflation rate of the country with the highest degree of price rigidity. Optimal fiscal policymaking results in a Home public spending gap that is more variable than the Foreign public spending gap. The reason is

\footnotetext{
${ }^{13}$ This can directly be seen by comparing the losses under commitment versus discretion when fiscal policy is restricted to be passive (see the columns $L^{c p}$ and $L^{d p}$ in Table 1).
} 
that Home's higher inflation variability forces its fiscal policy to assume a relatively larger role in stabilizing national inflation.

We now vary the correlation between the shocks. Here, we ignore the case of perfectly correlated supply shocks, because by Proposition 3, we know that it leads to zero welfare losses. Remember from (37) that it is only the relative supply shock (entering via the term $\left.\widetilde{T}_{t}-\widetilde{T}_{t-1}\right)$ that determines the fluctuations in the gaps of all variables. Hence, when the correlation of the supply shocks falls, the variance of the relative supply shock rises and the losses increase (as the figures in Table 1 confirm). The commonly-held view that in a monetary union the benefits from fiscal stabilization policy at the national level become proportionally larger when the shock correlations fall is nevertheless not correct for the current model. Table 1 shows that the ratios $L^{c} / L^{c p}$ and $L^{d} / L^{d p}$ remain unchanged when we vary the correlation of the supply shocks. The explanation for this finding is that the relative supply shocks effectively act as a common shock. Further, the welfare loss in this linear-quadratic framework is always proportional to the variance of this shock. Hence, the relative advantage of having recourse to fiscal stabilization is invariant to the correlation of the supply shocks. Nevertheless, it is interesting to vary the correlation of the supply shocks in the model, because we do not have a precise idea about their empirical correlation, while in this way we can see whether the gains from commitment and an active fiscal policy remain relevant when the correlation is positive. Holding everything else fixed at the benchmark setting, with a supply-shock correlation of 0.5 , the gain from commitment amounts roughly to a $0.4 \%$ permanent improvement in consumption, while the gain from an active fiscal policy is slightly larger (see Table 2).

We have also varied the $A R(1)$ coefficient of the supply shocks. In particular, we ran numerical simulations with $A R(1)$ coefficients of 0.9 and 0.75 . In both cases, we adjusted the variance of the innovations $\mu_{S, t}^{i}$, so as to keep the unconditional variance of $S_{t}^{i}$ unchanged. The gain from commitment amounts to a permanent consumption gain of $0.6 \%$ and $0.3 \%$, respectively, while the gain from using fiscal policy for stabilization amounts to a permanent consumption gain of $0.6 \%$ and $0.4 \%$, respectively. Hence, although smaller, the gains from commitment and an active fiscal policy remain non-trivial.

The next experiment concerns the variation of the coefficients $\lambda_{G H}$ and $\lambda_{G F}$ of the public spending gaps in the loss function. The reason for varying this coefficient is that we are ignorant about the appropriate size of this coefficient. As expected, increasing the coefficient leads to higher losses and lower variability in public spending. However, quantitatively, the gains from commitment and having access to fiscal stabilization remain relevant (see Table 2).

Finally, we explore the effects of changing the inverse of the elasticity of the labor supply, $\eta$. The appropriate size of this parameter is typically surrounded with a lot of uncertainty, so that it is sensible to consider this variation. Tables 1 and 2 report the results for $\eta=5$, thus assuming a labor-supply elasticity which is twice as large as the baseline elasticity. Although somewhat smaller than under the benchmark, the gains from 
commitment and fiscal stabilization remain non-negligible, as Table 2 shows.

\subsection{The rules}

As mentioned earlier, the advantage of a rule is that it may be easier to commit to than to the optimal policy, because a rule is often simpler and more transparent. The first combination of rules is suggested by the optimal solutions above. The monetary policy rule is chosen such that it (almost) closes the consumption gap and (almost) leads to zero world inflation. Of course, perfect elimination of the consumption gap and, hence, zero world inflation would be optimal, but would require some infinitely-large coefficients in the monetary policy rule. We approximate this situation by setting $b_{H}=b_{F}=b_{T}=0$ and choosing large values of $d_{H}, d_{F}=d_{H}(1-n) / n$ and $b_{C}$ in (35). ${ }^{14}$ With the consumption gap virtually eliminated, the public spending gap can be restricted to react to the termsof-trade gap, so that $g_{C H}=g_{C F}=0$ in (36). Table 1 reports the optimal coefficients of the public spending rules for the parameter combinations considered earlier. The optimal rules are characterized by $g_{T H}=g_{T F}>0$. We observe that in all the cases reported, the optimal fiscal rule leads to a welfare loss (denoted $L^{r}$ ) below the loss under the fulloptimization discretionary policy. Note also that, for the baseline case, the loss from having passive fiscal policies (i.e., also $g_{T H}=g_{T F}=0$, with the loss denoted by $L^{r p}$ ), is (virtually) equal to that under passive fiscal policies when monetary policy is optimally conducted under commitment (compare columns $C P$ and $R P$ in Table 2). ${ }^{15}$ As before, fiscal policy is employed to reduce the effect of the terms of trade on local inflation and, with differences in price rigidity, the more flexible country employs a more active fiscal policy. Finally, the rule coefficients are unaffected by the shock correlations. This mirrors the result that the relative losses under optimal policymaking with or without active fiscal policy are invariant to the shock correlations.

The second combination of rules is based on output gaps. Monetary policy follows a standard Taylor rule, with the original coefficients proposed by Taylor (1993):

$$
\widehat{R}_{t}-\widetilde{R}_{t}=1.5 \pi_{t}^{W}+0.5\left(\widehat{Y}_{t}^{W}-\widetilde{Y}_{t}^{W}\right)
$$

This is sometimes seen as a reasonable description of how monetary policy has been conducted in the past, in particular in the U.S. Because fiscal policy is often discussed in terms of its pro- or countercyclicality (that is, the degree to which it is correlated with

\footnotetext{
${ }^{14}$ When the parameters $d_{H}$ and $d_{F}$ are chosen too large, a unique saddlepath solution no longer exists. This reflects a well-known feature of this type of model: to ensure determinacy, the nominal interest rule should be "active," but not too active (see, e.g., Woodford, 2002). Raising $b_{C}$ reduces the consumption gap further and forces world inflation closer to zero.

${ }^{15}$ If we restrict ourselves to an analysis of only rule-based policies, a measure of the loss of this fiscal restriction would be a comparison of $L^{r}$ and $L^{r p}$. For the benchmark case, the difference corresponds to a permanent drop in consumption of around 0.5 percentage points.
} 
the output gap), the public spending gaps are set according to: ${ }^{16}$

$$
\widehat{G}_{t}^{H}-\widetilde{G}_{t}^{H}=-g_{Y H}\left(\widehat{Y}_{t}^{H}-\widetilde{Y}_{t}^{H}\right), \quad \widehat{G}_{t}^{F}-\widetilde{G}_{t}^{F}=-g_{Y F}\left(\widehat{Y}_{t}^{F}-\widetilde{Y}_{t}^{F}\right) .
$$

We report the results for the combination of rules (40) and (41) in Table 3. The losses with completely passive fiscal policies (i.e., $g_{Y H}=g_{Y F}=0$ ) are close to the corresponding losses under the (approximate) optimal monetary policy rule (compare the losses reported in the columns under $L^{r p}$ in Tables 1 and 3). Hence, a Taylor rule as such performs well in this model. To explore the contribution to stabilization of output-gap based fiscal rules we find the optimal coefficients $g_{Y H}$ and $g_{Y F}$, while monetary policy follows the standard Taylor rule. The optimal fiscal rules are always countercyclical. For the baseline parameter combination, a 1 percentage point increase in the output gap leads to a reduction in the spending gap of about 1.3 percentage point. In welfare terms, this combination of rules performs well, as it attains welfare levels close to those for the optimal fiscal rule combined with the (approximate) optimal monetary policy as reported in Table 1.

We may compare the fiscal rules based on the output gap with what the empirical literature finds for the correlation between public spending and the business cycle. Several authors have recently investigated this for European countries and/or OECD countries. In his study of Irish fiscal policy, Lane (1998) finds evidence that aggregate public spending has been acyclical. Lane (2002) explores the cyclicality of fiscal policy for OECD countries and concludes that aggregate public spending is mildly countercyclical. The degree of countercyclicality varies across countries and across spending categories, though countries with more volatile output and dispersed political power are the most likely ones to run a countercyclical fiscal policy. Fatás and Mihov (2000, 2001) explore the propagation of fiscal policy changes and conclude that they have strong and persistent effects on economic activity and consumption.

Under the optimal policies we analyzed earlier, we found that with differences in price stickiness, monetary policy induced relatively more stable prices in the country with the higher degree of price rigidity. Here, we investigate this policy implication in the context of the Taylor rule for monetary policy. In (40), we therefore replace $\pi_{t}^{W}=n \pi_{t}^{H}+(1-n) \pi_{t}^{H}$ by $\pi_{t}^{W *} \equiv \delta_{H} \pi_{t}^{H}+\delta_{H} \pi_{t}^{F}$, and we compute the optimal combination of relative weights $\left(\delta_{H}^{o p t}, \delta_{F}^{o p t}\right)$ assuming that fiscal policies follow the output gap-based rules (41). Again, this yields a special case of the combination (35) and (36). Based on the asymmetric case of $\left(\alpha^{H}, \alpha^{F}\right)=(0.5,0.75)$, Table 4 reports the results for different degrees of correlation of the supply shocks and different weights on public spending in the loss function. Except for the 2nd and 3rd lines of the table, which assume a passive fiscal policy, in the other

\footnotetext{
${ }^{16}$ Note that the combination (40) and (41) is a special case of the combination (35) and (36), because $\left(\widehat{Y}_{t}^{H}-\tilde{Y}_{t}^{H}\right)$ and $\left(\widehat{Y}_{t}^{F}-\widetilde{Y}_{t}^{F}\right)$ can be expressed in terms of consumption, public spending and terms-oftrade gaps. For example, if $g_{Y H}=g_{Y F} \equiv g_{Y}$, we can rewrite (40) and (41) into the format (35) and (36), with coefficient restrictions $g_{C H}=g_{C F}=\frac{g_{Y} \xi_{c}}{1+g_{Y}\left(1-\xi_{c}\right)}, g_{T H}=\frac{g_{Y} \xi_{c}(1-n)}{1+g_{Y}\left(1-\xi_{c}\right)}, g_{T F}=\frac{g_{Y} \xi_{c} n}{1+g_{Y}\left(1-\xi_{c}\right)}, b_{H}=1.5 n$, $b_{F}=1.5(1-n), b_{C}=\frac{\xi_{c} b_{Y}}{1+g_{Y}\left(1-\xi_{c}\right)}, b_{T}=0$ and $d_{H}=d_{F}=0$.
} 
lines we take for the coefficients $g_{Y H}$ and $g_{Y F}$ the optimal ones that are reported in Table 3 for the corresponding parameter setting. Table 4 shows that it is indeed optimal in all cases to give a higher relative weight to the stickier price country. However, the optimal relative weights are very close to the original weights $(n, 1-n)$ for $\pi_{t}^{H}$ and $\pi_{t}^{F}$, respectively. Accordingly, the welfare losses are very close to the corresponding losses found in Table 3. Therefore, it seems that if the central bank of a monetary union follows a policy that is close to the standard Taylor rule, there is actually little reason to adjust the relative weights of the individual components of the union-wide inflation measure for asymmetries in nominal rigidities. The gains would only be small, while the political resistance to such a reweighting would most likely be substantial. ${ }^{17}$ In addition, having more rigid countries enter with a larger relative weight could weaken their incentive to make their product markets more flexible (as argued by Benigno, 2002).

Countries sometimes call upon each other to take fiscal measures that get the (world) economy out of recession. ${ }^{18}$ One such type of "cooperative rule" would be to have fiscal policy depend (linearly) on the world output gap, rather than the national output gap. If the world output gap is negative, fiscal policy would be expansionary, and vice versa. Because these fiscal rules do not react to national circumstances and are, therefore, unable to affect country-specific fluctuations in inflation, their contribution to reducing welfare losses will be marginal. In particular, when monetary policy is able to close the consumption gap, such fiscal rules are redundant. Hence, we do not report results for these rules.

\section{Conclusion}

This paper has explored the interactions between monetary and fiscal policy in a microfounded model of a monetary union with sticky prices. We explored the contribution of public purchases in economic stabilization in the presence of supply and demand shocks. This is an important issue in EMU, given that monetary policy is constrained to be attuned to European-wide economic developments. This is often considered to be the main drawback of EMU. In selecting fiscal policies, either optimal or through a rule, we took a European-wide perspective. This is the relevant perspective to be taken by supranational European institutions, in particular the ECB and the European Commission, the latter of which has to take initiatives on economic policies that promote welfare across the European Union. It is also the relevant perspective for the ECOFIN Council (or the Eurogroup) in case it moves towards more explicit coordination of fiscal policies. Our results suggest that there are non-negligible gains from fiscal stabilization and commitment.

\footnotetext{
${ }^{17}$ We experimented with an increase in the coefficient on $\pi_{t}^{W *}$ in the central bank's interest rate rule. This raised the optimal relative weight of the more rigid country in $\pi_{t}^{W *}$, which corresponds to what Benigno's (2001) finds for a strict inflation targeting rule (i.e., such that $\pi_{t}^{W *}=0$ ).

${ }^{18}$ An example is the Bonn Agreement of 1978 in which the G5 countries intended to give a coordinated fiscal stimulus to a stagnant world economy (without aggravating external imbalances).
} 
While there is a pressure for more fiscal coordination in Europe, actual fiscal policies are primarily conducted with the objective of serving national interests rather than union-wide interests. Therefore, further research could extend the current framework into one where national fiscal policies interact strategically. A relevant question then is whether current union-wide institutions, in particular the Stability and Growth Pact, suffice to induce fiscal policymakers to take into account the union-wide implications of their policies. ${ }^{19}$ More generally, one would want to assess more firmly the gains from fiscal policy cooperation in a monetary union.

The analysis in this paper can be extended into various other directions. One is to relax the assumption of Ricardian equivalence and allow for a richer menu of fiscal policies. In particular, public debt can be employed as an instrument to intertemporally smooth out the effects of shocks. It will be interesting to investigate how this combines with the use of public spending to stabilize current demand. Deficit ceilings, like those imposed under the Stability and Growth Pact will then also become relevant from a welfare perspective. Further, one would expect that the interaction between monetary and fiscal policy strengthens and that time consistency problems may deepen when the time profile of the taxes and/or transfers is no longer irrelevant and debt is nominal. Also issues arise that pertain to the fiscal restrictions needed to provide the central bank with control over the price level (Sims, 1999). Another extension would abolish the assumption of complete markets. When centralized to a sufficient extent, fiscal policies could then be employed to provide for the sharing of country-specific risks. A third extension would allow not only for sticky prices, but also for sticky wages (e.g., Erceg et al., 2000). As a result, optimal policies would need to address more distortions. As a fourth elaboration on the current setup, one could introduce a time-varying mark up (along the lines of Clarida et al., 2002), thereby giving rise to a "cost-push" shock in the Phillips curves, which again would imply more distortions to be addressed. Finally, the model can be made more realistic by introducing lags in the transmission of policy, which is especially relevant for the implementation of fiscal policy. There is a strong consensus that implementing fiscal policy actions takes much more time than changing monetary policy. For example, measures have to be designed, presented to the parliament and to be voted on. Thus, there is doubt about the extent to which fiscal policy can be used to fine-tune the economy.

The suggested extensions will all affect the usefulness of fiscal policy as an instrument for macroeconomic stabilization. While the last extension may reduce the gains from fiscal stabilization, the combination of incomplete markets and asymmetric demand shocks could provide an additional role for fiscal stabilization policies. We leave these extensions for future research and view our analysis as a potentially useful benchmark for further analyses of the monetary and fiscal policy mix in a monetary union.

\section{Appendices}

\footnotetext{
${ }^{19}$ Benigno and Benigno (2001) explore a similar issue for monetary policy in their model.
} 


\section{A Derivation of the efficient flex-price equilibrium}

Log-linearizing (15) around the steady state, and using the relevant definitions from the main text, we have:

$$
-\rho\left(\widetilde{C}_{t}^{H}+D_{t}^{H}\right)=(1-n) \widetilde{T}_{t}+\eta\left[(1-n) \xi_{c} \widetilde{T}_{t}+\xi_{c} \widetilde{C}_{t}^{W}+\left(1-\xi_{c}\right) \widetilde{G}_{t}^{H}\right]-\eta S_{t}^{H},
$$

and an analogous equation for the Foreign country:

$$
-\rho\left(\widetilde{C}_{t}^{F}+D_{t}^{F}\right)=-n \widetilde{T}_{t}+\eta\left[-n \xi_{c} \widetilde{T}_{t}+\xi_{c} \widetilde{C}_{t}^{W}+\left(1-\xi_{c}\right) \widetilde{G}_{t}^{F}\right]-\eta S_{t}^{F}
$$

Taking a weighted average (with weights $n$ and $1-n$ ) of the latter two equations, we obtain $-\rho\left(\widetilde{C}_{t}^{W}+D_{t}^{W}\right)=\eta\left[\xi_{c} \widetilde{C}_{t}^{W}+\left(1-\xi_{c}\right) \widetilde{G}_{t}^{W}\right]-\eta S_{t}^{W}$. Hence,

$$
\widetilde{C}_{t}^{W}=\frac{\eta}{\rho+\eta \xi_{c}}\left[S_{t}^{W}-\frac{\rho}{\eta} D_{t}^{W}-\left(1-\xi_{c}\right) \widetilde{G}_{t}^{W}\right] .
$$

Subtracting (43) from (42) and using that $\widetilde{C}_{t}^{H}+D_{t}^{H}=\widetilde{C}_{t}^{F}+D_{t}^{F}$ [as follows by linearizing (8)] we obtain $0=\widetilde{T}_{t}+\eta\left[\xi_{c} \widetilde{T}_{t}-\left(1-\xi_{c}\right) \widetilde{G}_{t}^{R}\right]+\eta S_{t}^{R}$ and thus

$$
\widetilde{T}_{t}=\frac{\eta}{1+\eta \xi_{c}}\left[\left(1-\xi_{c}\right) \widetilde{G}_{t}^{R}-S_{t}^{R}\right] .
$$

Further, because $\widetilde{Y}_{t}^{H}=\left[(1-n) \bar{T}^{1-n} \bar{C} \widetilde{T}_{t}+\bar{T}^{1-n} \bar{C} \widetilde{C}_{t}^{W}+\bar{G}^{H} \widetilde{G}_{t}^{H}\right] / \bar{Y}^{H}$, we can also write $(42)$ as $-\rho\left(\widetilde{C}_{t}^{H}+D_{t}^{H}\right)=(1-n) \widetilde{T}_{t}+\eta \widetilde{Y}_{t}^{H}-\eta S_{t}^{H}$ and $(43)$ as $-\rho\left(\widetilde{C}_{t}^{F}+D_{t}^{F}\right)=$ $-n \widetilde{T}_{t}+\eta \widetilde{Y}_{t}^{F}-\eta S_{t}^{F}$. Taking a weighted average (with weights $n$ and $1-n$ ) of these two equations, we then obtain

$$
-\rho\left(\widetilde{C}_{t}^{W}+D_{t}^{W}\right)=\eta \widetilde{Y}_{t}^{W}-\eta S_{t}^{W}
$$

Combining this with (44), we find that:

$$
\widetilde{Y}_{t}^{W}=\frac{\eta \xi_{c}}{\rho+\eta \xi_{c}} S_{t}^{W}-\frac{\rho \xi_{c}}{\rho+\eta \xi_{c}} D_{t}^{W}+\frac{\rho\left(1-\xi_{c}\right)}{\rho+\eta \xi_{c}} \widetilde{G}_{t}^{W} .
$$

We solve now for $\widetilde{G}_{t}^{H}$ and $\widetilde{G}_{t}^{F}$, thereby completing the solution of the efficient flex-price equilibrium. The fiscal authorities maximize (20) over $G_{t}^{H}$ and $G_{t}^{F}$, where it is understood that the values of $C_{t}^{H}, Y_{t}^{H}, C_{t}^{F}$, and $Y_{t}^{F}$ satisfy the private-sector optimality conditions (15) and (16). Differentiating (20) with respect to $G_{t}^{H}$ yields the first-order condition:

$$
\begin{aligned}
& \mathrm{E}_{t} \sum_{s=t}^{\infty} \beta^{s-t}\left[n U_{C}\left(C_{s}^{H}, \epsilon_{s}^{H}\right) \frac{\partial C_{s}^{H}}{\partial G_{t}^{H}}+(1-n) U_{C}\left(C_{s}^{F}, \epsilon_{s}^{F}\right) \frac{\partial C_{s}^{F}}{\partial G_{t}^{H}}\right]+n V_{G}\left(G_{t}^{H}\right) \\
& -\mathrm{E}_{t} \sum_{s=t}^{\infty} \beta^{s-t}\left\{n v_{y}\left(Y_{s}^{H}, z_{s}^{H}\right)\left[(1-n) T_{s}^{-n} C_{s}^{W} \frac{\partial T_{s}}{\partial G_{t}^{H}}+T_{s}^{1-n} \frac{\partial C_{s}^{W}}{\partial G_{t}^{H}}\right]\right\}+n v_{y}\left(Y_{t}^{H}, z_{t}^{H}\right) \\
& -\mathrm{E}_{t} \sum_{s=t}^{\infty} \beta^{s-t}\left\{(1-n) v_{y}\left(Y_{s}^{F}, z_{s}^{F}\right)\left[(-n) T_{s}^{-(n+1)} C_{s}^{W} \frac{\partial T_{s}}{\partial G_{t}^{H}}+T_{s}^{-n} \frac{\partial C_{s}^{W}}{\partial G_{t}^{H}}\right]\right\} \\
& =0 .
\end{aligned}
$$


Combining (8), (15), (16) and (17), we have that $T_{s} v_{y}\left(Y_{s}^{H}, z_{s}^{H}\right)=v_{y}\left(Y_{s}^{F}, z_{s}^{F}\right)$, for all $s \geq$ $t$. Using this along with the fact that $\partial C_{t}^{W} / \partial G_{t}^{H}=n\left(\partial C_{t}^{H} / \partial G_{t}^{H}\right)+(1-n)\left(\partial C_{t}^{F} / \partial G_{t}^{H}\right)$, all $t$, and again (15) and (16), with (17) imposed, we can simplify (48) to

$$
V_{G}\left(G_{t}^{H}\right)=v_{y}\left(Y_{t}^{H}, z_{t}^{H}\right)
$$

We log-linearize this and find $-\rho_{g} \widetilde{G}_{t}^{H}=\eta\left[(1-n) \xi_{c} \widetilde{T}_{t}+\xi_{c} \widetilde{C}_{t}^{W}+\left(1-\xi_{c}\right) \widetilde{G}_{t}^{H}\right]-\eta S_{t}^{H}$, from which we obtain

$$
\widetilde{G}_{t}^{H}=\frac{\eta}{\rho_{g}+\eta\left(1-\xi_{c}\right)}\left[S_{t}^{H}-\xi_{c}\left((1-n) \widetilde{T}_{t}+\widetilde{C}_{t}^{W}\right)\right]
$$

For Foreign spending we similarly find

$$
\widetilde{G}_{t}^{F}=\frac{\eta}{\rho_{g}+\eta\left(1-\xi_{c}\right)}\left[S_{t}^{F}-\xi_{c}\left(-n \widetilde{T}_{t}+\widetilde{C}_{t}^{W}\right)\right] .
$$

Together with (44) and (45), for the flexible equilibrium, we then have four equations in four unknowns: $\widetilde{G}_{t}^{H}, \widetilde{G}_{t}^{F}, \widetilde{T}_{t}$ and $\widetilde{C}_{t}^{W}$. Using (49) and (50), we get $\widetilde{G}_{t}^{R}=\frac{\eta}{\rho_{g}+\eta\left(1-\xi_{c}\right)}\left(S_{t}^{R}+\xi_{c} \widetilde{T}_{t}\right)$. By substituting this into (45), one then recovers (25). Next, combining (49) and (50) with weights $n$ and $(1-n)$, respectively, gives $\widetilde{G}_{t}^{W}=\frac{\eta}{\rho_{g}+\eta\left(1-\xi_{c}\right)}\left(S_{t}^{W}-\xi_{c} \widetilde{C}_{t}^{W}\right)$. Combining this with (44) and solving gives (23). Substituting (23) back into (44) and working out yields $(22)$.

\section{B Derivation of (30)}

We can write (11), for $i=H$ and $j=h$, as

$$
0=\mathrm{E}_{t} \sum_{k=0}^{\infty}\left(\alpha^{H} \beta\right)^{k}\left\{\left[\lambda_{t+k} p_{t}(h)+v_{y}\left(y_{t, t+k}(h), z_{t+k}^{H}\right)\right] y_{t, t+k}(h)\right\},
$$

where we have imposed (17). After substituting for $\lambda_{t+k}$ we obtain

$$
\mathrm{E}_{t} \sum_{k=0}^{\infty}\left(\alpha^{H} \beta\right)^{k}\left\{\left[U_{C}\left(C_{t+k}^{H}, \epsilon_{t+k}^{H}\right) \frac{p_{t}(h)}{P_{H, t+k}} T_{t+k}^{n-1}+v_{y}\left(y_{t, t+k}(h), z_{t+k}^{H}\right)\right] y_{t, t+k}(h)\right\}=0 .
$$

We log-linearize this condition around the steady state and, using the relevant definitions from the main text, we obtain

$$
0=\mathrm{E}_{t} \sum_{k=0}^{\infty}\left(\alpha^{H} \beta\right)^{k}\left\{\begin{array}{c}
\widehat{p}_{t, t+k}-(1-n) \widehat{T}_{t+k}-\rho\left(\widehat{C}_{t+k}^{H}+D_{t+k}^{H}\right) \\
-\eta\left[-\sigma \widehat{p}_{t, t+k}+\xi_{c}\left((1-n) \widehat{T}_{t+k}+\widehat{C}_{t+k}^{H}\right)+\left(1-\xi_{c}\right) \widehat{G}_{t+k}^{H}-S_{t+k}^{H}\right]
\end{array}\right\} .
$$

We rewrite this expression, using that $\widehat{p}_{t, t+k}=\widehat{p}_{t, t}-\sum_{s=1}^{k} \pi_{t+s}^{H}$ :

$$
\begin{aligned}
\frac{\widehat{p}_{t, t}}{1-\alpha^{H} \beta}= & \mathrm{E}_{t} \sum_{k=0}^{\infty}\left(\alpha^{H} \beta\right)^{k}\left\{\begin{array}{r}
\frac{1+\eta \xi_{c}}{1+\eta \sigma}(1-n) \widehat{T}_{t+k}+\frac{\rho+\eta \xi_{c}}{1+\eta \sigma} \widehat{C}_{t+k}^{H}+\frac{\rho}{1+\eta \sigma} D_{t+k}^{H} \\
+\frac{\eta}{1+\eta \sigma}\left(\left(1-\xi_{c}\right) \widehat{G}_{t+k}^{H}-S_{t+k}^{H}\right)
\end{array}\right\} \\
& +\mathrm{E}_{t} \sum_{k=0}^{\infty}\left(\alpha^{H} \beta\right)^{k}\left[\sum_{s=1}^{k} \pi_{t+s}^{H}\right] .
\end{aligned}
$$


Log-linearizing (12), we obtain $\widehat{p}_{t, t}=\frac{\alpha^{H}}{1-\alpha^{H}} \pi_{t}^{H}$, which we use to simplify the previous expression:

$$
\begin{aligned}
\frac{\pi_{t}^{H}}{1-\alpha^{H} \beta} \frac{\alpha^{H}}{1-\alpha^{H}}= & \mathrm{E}_{t} \sum_{k=0}^{\infty}\left(\alpha^{H} \beta\right)^{k}\left\{\begin{array}{r}
\frac{1+\eta \xi_{c}}{1+\eta \sigma}(1-n) \widehat{T}_{t+k}+\frac{\rho+\eta \xi_{c}}{1+\eta \sigma} \widehat{C}_{t+k}^{H}+\frac{\rho}{1+\eta \sigma} D_{t+k}^{H} \\
+\frac{\eta}{1+\eta \sigma}\left(\left(1-\xi_{c}\right) \widehat{G}_{t+k}^{H}-S_{t+k}^{H}\right)
\end{array}\right. \\
& +\mathrm{E}_{t} \sum_{k=1}^{\infty}\left(\alpha^{H} \beta\right)^{k} \frac{\pi_{t+k}^{H}}{1-\alpha^{H} \beta} .
\end{aligned}
$$

Finally, we then obtain

$$
\pi_{t}^{H}=\frac{\left(1-\alpha^{H} \beta\right)\left(1-\alpha^{H}\right)}{\alpha^{H}}\left[\begin{array}{c}
\frac{1+\eta \xi_{c}}{1+\eta \sigma}(1-n) \widehat{T}_{t}+\frac{\rho+\eta \xi_{c}}{1+\eta \sigma} \widehat{C}_{t}^{H}+\frac{\eta\left(1-\xi_{c}\right)}{1+\eta \sigma} \widehat{G}_{t}^{H} \\
+\frac{\rho}{1+\eta \sigma} D_{t}^{H}-\frac{\eta}{1+\eta \sigma} S_{t}^{H}
\end{array}\right]+\beta \mathrm{E}_{t} \pi_{t+1}^{H} .
$$

Combine (46), (47) and the fact that $\widetilde{C}_{t}^{W}+D_{t}^{W}=\widetilde{C}_{t}^{H}+D_{t}^{H}$, to find that $\widetilde{C}_{t}^{H}=$ $\frac{\eta}{\rho+\eta \xi_{c}} S_{t}^{W}+\frac{\eta \xi_{c}}{\rho+\eta \xi_{c}} D_{t}^{W}-\frac{\eta\left(1-\xi_{c}\right)}{\rho+\eta \xi_{c}} \widetilde{G}_{t}^{W}-D_{t}^{H}$. Using this expression and (45), it is straightforward to show (without working out the expressions for the efficient flex-price public spending levels $)$ that $-\left(1+\eta \xi_{c}\right)(1-n) \widetilde{T}_{t}-\left(\rho+\eta \xi_{c}\right) \widetilde{C}_{t}^{H}-\eta\left(1-\xi_{c}\right) \widetilde{G}_{t}^{H}=\rho D_{t}^{H}-\eta S_{t}^{H}$. Hence, also using that $\widehat{C}_{t}^{W}-\widetilde{C}_{t}^{W}=\widehat{C}_{t}^{H}-\widetilde{C}_{t}^{H},(51)$ can be rewritten as (30). For Foreign, we can derive a similar expression.

\section{Characterization of optimal policies}

To solve for the optimal policies under commitment we set up the relevant Lagrangian (see, e.g., Woodford, 1999a):

$$
\begin{aligned}
\mathcal{L}= & \mathrm{E}_{t} \sum_{s=t}^{\infty} \beta^{s-t}\left\{L_{t}+2 \phi_{1, s}\left[\pi_{s}^{H}-\beta \pi_{s+1}^{H}-k_{T}^{H}\left(\widehat{T}_{s}-\widetilde{T}_{s}\right)-k_{C}^{H}\left(\widehat{C}_{s}^{W}-\widetilde{C}_{s}^{W}\right)-k_{G}^{H}\left(\widehat{G}_{s}^{H}-\widetilde{G}_{s}^{H}\right)\right]\right. \\
& +2 \phi_{2, s}\left[\pi_{s}^{F}-\beta \pi_{s+1}^{F}+k_{T}^{F}\left(\widehat{T}_{s}-\widetilde{T}_{s}\right)-k_{C}^{F}\left(\widehat{C}_{s}^{W}-\widetilde{C}_{s}^{W}\right)-k_{G}^{F}\left(\widehat{G}_{s}^{F}-\widetilde{G}_{s}^{F}\right)\right] \\
& \left.+2 \phi_{3, s}\left[\left(\widehat{T}_{s}-\widetilde{T}_{s}\right)-\left(\widehat{T}_{s-1}-\widetilde{T}_{s-1}\right)-\pi_{s}^{F}+\pi_{s}^{H}-\left(\widetilde{T}_{s}-\widetilde{T}_{s-1}\right)\right],\right\}
\end{aligned}
$$

where $k_{T}^{H} \equiv k^{H}\left(1+\eta \xi_{c}\right)(1-n), k_{C}^{H} \equiv k^{H}\left(\rho+\eta \xi_{c}\right), k_{G}^{H} \equiv k^{H} \eta\left(1-\xi_{c}\right), k_{T}^{F} \equiv k^{F}\left(1+\eta \xi_{c}\right) n$, $k_{C}^{F} \equiv k^{F}\left(\rho+\eta \xi_{c}\right), k_{G}^{F} \equiv k^{F} \eta\left(1-\xi_{c}\right)$ and where $2 \phi_{1, s}, 2 \phi_{2, s}$, and $2 \phi_{3, s}$ are the multipliers on (30), (31), and (32), respectively. Optimizing over $\widehat{C}_{s}^{W}-\widetilde{C}_{s}^{W}, \pi_{s}^{H}, \pi_{s}^{F}, \widehat{G}_{s}^{H}-\widetilde{G}_{s}^{H}$, $\widehat{G}_{s}^{F}-\widetilde{G}_{s}^{F}$, and $\widehat{T}_{s}-\widetilde{T}_{s}$ yields six necessary first-order conditions, which after some manip- 
ulation imply the following optimality conditions (or targeting rules):

$$
\begin{aligned}
\lambda_{C}\left(\widehat{C}_{t}^{W}-\widetilde{C}_{t}^{W}\right) & =\frac{\lambda_{G H} k_{C}^{H}}{k_{G}^{H}}\left(\widehat{G}_{t}^{H}-\widetilde{G}_{t}^{H}\right)+\frac{\lambda_{G F} k_{C}^{F}}{k_{G}^{F}}\left(\widehat{G}_{t}^{F}-\widetilde{G}_{t}^{F}\right), \\
\lambda_{\pi^{H}} \pi_{t}^{H} & =-\frac{\lambda_{G H}}{k_{G}^{H}}\left[\left(\widehat{G}_{t}^{H}-\widetilde{G}_{t}^{H}\right)-\left(\widehat{G}_{t-1}^{H}-\widetilde{G}_{t-1}^{H}\right)\right]-\phi_{3, t}, \\
\lambda_{\pi^{F}} \pi_{t}^{F} & =-\frac{\lambda_{G F}}{k_{G}^{F}}\left[\left(\widehat{G}_{t}^{F}-\widetilde{G}_{t}^{F}\right)-\left(\widehat{G}_{t-1}^{F}-\widetilde{G}_{t-1}^{F}\right)\right]+\phi_{3, t}, \\
\phi_{3, t} & =\beta \mathrm{E}_{t} \phi_{3, t+1}-\lambda_{T}\left(\widehat{T}_{t}-\widetilde{T}_{t}\right)+\frac{\lambda_{G H} k_{T}^{H}}{k_{G}^{H}}\left(\widehat{G}_{t}^{H}-\widetilde{G}_{t}^{H}\right)-\frac{\lambda_{G F} k_{T}^{F}}{k_{G}^{F}}\left(\widehat{G}_{t}^{F}-\widetilde{G}_{t}^{F}\right) .
\end{aligned}
$$

At any period $t$, equations (52)-(55) and (30)-(32) determine the optimal evolution of the variables with commitment under the "timeless principle" (Woodford, 1999b); i.e., the Lagrange multipliers are not set at zero at $t-1$, which would render the solution dependent upon the particular date the commitment plan is implemented. Equation (52) resembles a standard public finance efficiency condition. Equations (53) and (54), which provide the optimal trade-offs among national inflation, government spending gaps and the terms-of-trade gap, ${ }^{20}$ reveal the inertia of the public spending gaps. Without commitment, the lagged spending gaps would be absent from these equations. Inflationary pressures are thus met with a prolonged fiscal contraction, which helps to dampen inflation via the effect on expected future inflation. ${ }^{21}$

Now, consider the case of complete symmetry, so that $\alpha^{H}=\alpha^{F}$ and $n=1 / 2$. Hence, $k^{H}=k^{F}$ and, hence, $k_{T}^{H}=k_{T}^{F} \equiv k_{T}, k_{G}^{H}=k_{G}^{F} \equiv k_{G}$ and $k_{C}^{H}=k_{C}^{F} \equiv k_{C}$. Further, let $\lambda_{G H}=\lambda_{G F} \equiv \lambda_{G}$. Then, (52) becomes $\lambda_{C}\left(\widehat{C}_{t}^{W}-\widetilde{C}_{t}^{W}\right)=\frac{\lambda_{G} k_{C}}{k_{G}}\left[\left(\widehat{G}_{t}^{H}-\widetilde{G}_{t}^{H}\right)+\left(\widehat{G}_{t}^{F}-\widetilde{G}_{t}^{F}\right)\right]$. This confirms that, when monetary policy closes the consumption gap, then $\left(\widehat{G}_{t}^{H}-\widetilde{G}_{t}^{H}\right)=$ $-\left(\widehat{G}_{t}^{F}-\widetilde{G}_{t}^{F}\right)$. With equal rigidities $\lambda_{\pi^{H}}=n$ and $\lambda_{\pi^{F}}=1-n$, and from (53) and (54), we then obtain an equation for world inflation:

$$
\pi_{t}^{W}=-\frac{\lambda_{G}}{k_{G}}\left\{\left[\left(\widehat{G}_{t}^{H}-\widetilde{G}_{t}^{H}\right)-\left(\widehat{G}_{t-1}^{H}-\widetilde{G}_{t-1}^{H}\right)\right]+\left[\left(\widehat{G}_{t}^{F}-\widetilde{G}_{t}^{F}\right)-\left(\widehat{G}_{t-1}^{F}-\widetilde{G}_{t-1}^{F}\right)\right]\right\} .
$$

This confirms that, when $\left(\widehat{G}_{t}^{H}-\widetilde{G}_{t}^{H}\right)=-\left(\widehat{G}_{t}^{F}-\widetilde{G}_{t}^{F}\right), \pi_{t}^{W}=0$ at all dates. However, from the system of equations, we observe that national inflation rates cannot be stabilized when supply shocks move $\widetilde{T}_{t}$. (A proof by contradiction can be constructed along the lines of that of Proposition 4.)

\footnotetext{
${ }^{20}$ The latter affects the trade off via $\phi_{3, t}$, the marginal loss of the terms-of-trade gap. Due to the dynamics of the latter, $\phi_{3, t}$ is a discounted sum of all current and expected future terms-of-trade and public spending gaps; cf. (55). (Spending gaps enter as they are proportional to the marginal losses of the terms of trade in terms of local inflation, i.e., the multipliers $\phi_{1, t}$ and $\phi_{2, t}$, respectively.)

${ }^{21}$ This is analogous to the targeting rule under commitment obtained in the closed-economy model without fiscal policy (e.g., see Clarida et al., 1999): $\pi_{t}=-\chi\left(x_{t}-x_{t-1}\right), \chi>0$, where $x_{t}$ is the output gap.
} 


\section{Tables}

Table 1: Expected welfare losses under optimal policies and optimal rule coefficients.

\begin{tabular}{|l|l|l|l|l|l|l|l|}
\hline$\left(\alpha^{H}, \rho_{S}, \eta, \lambda_{G}\right)$ & $L^{c}$ & $L^{d}$ & $L^{c p}$ & $L^{d p}$ & $L^{r}$ & $L^{r p}$ & $\left(g_{T H}^{\text {opt }}, g_{T F}^{\text {opt }}\right)$ \\
\hline \hline baseline & 0.6691 & 0.7248 & 0.7417 & 0.7417 & 0.6943 & 0.7417 & $(0.37,0.37)$ \\
\hline$\left(0.75,0.5,10, \lambda_{G}^{B}\right)$ & 0.3345 & 0.3624 & 0.3708 & 0.3708 & 0.3472 & 0.3708 & $(0.37,0.37)$ \\
\hline$\left(0.75,-1,10, \lambda_{G}^{B}\right)$ & 1.3381 & 1.4497 & 1.4834 & 1.4834 & 1.3886 & 1.4834 & $(0.37,0.37)$ \\
\hline$\left(0.5,0,10, \lambda_{G}^{B}\right)$ & 0.8042 & 0.8575 & 0.8747 & 0.8864 & 0.8382 & 0.8911 & $(0.41,0.30)$ \\
\hline$\left(0.5,-1,10, \lambda_{G}^{B}\right)$ & 1.6084 & 1.7150 & 1.7494 & 1.7727 & 1.6764 & 1.7821 & $(0.41,0.30)$ \\
\hline \hline$\left(0.75,0,10, \frac{1}{2} \lambda_{G}^{B}\right)$ & 0.6263 & 0.7091 & 0.7417 & 0.7417 & 0.6567 & 0.7417 & $(0.62,0.62)$ \\
\hline$\left(0.75,-1,10, \frac{1}{2} \lambda_{G}^{B}\right)$ & 1.2525 & 1.4181 & 1.4834 & 1.4834 & 1.3133 & 1.4834 & $(0.62,0.62)$ \\
\hline$\left(0.5,0,10, \frac{1}{2} \lambda_{G}^{B}\right)$ & 0.7609 & 0.8329 & 0.8747 & 0.8864 & 0.7998 & 0.8911 & $(0.64,0.55)$ \\
\hline$\left(0.5,-1,10, \frac{1}{2} \lambda_{G}^{B}\right)$ & 1.5217 & 1.6659 & 1.7494 & 1.7727 & 1.5996 & 1.7821 & $(0.64,0.55)$ \\
\hline \hline$\left(0.75,0,10,2 \lambda_{G}^{B}\right)$ & 0.6999 & 0.7331 & 0.7417 & 0.7417 & 0.7167 & 0.7417 & $(0.20,0.20)$ \\
\hline$\left(0.75,-1,10,2 \lambda_{G}^{B}\right)$ & 1.3999 & 1.4663 & 1.4834 & 1.4834 & 1.4334 & 1.4834 & $(0.20,0.20)$ \\
\hline$\left(0.5,0,10,2 \lambda_{G}^{B}\right)$ & 0.8346 & 0.8713 & 0.8747 & 0.8864 & 0.8623 & 0.8911 & $(0.24,0.15)$ \\
\hline$\left(0.5,-1,10,2 \lambda_{G}^{B}\right)$ & 1.6692 & 1.7426 & 1.7494 & 1.7727 & 1.7245 & 1.7821 & $(0.24,0.15)$ \\
\hline \hline$\left(0.75,0,5, \lambda_{G}^{B}\right)$ & 0.6013 & 0.6415 & 0.6533 & 0.6533 & 0.6205 & 0.6533 & $(0.33,0.33)$ \\
\hline$\left(0.75,-1,5, \lambda_{G}^{B}\right)$ & 1.2026 & 1.2830 & 1.3067 & 1.3067 & 1.2411 & 1.3067 & $(0.33,0.33)$ \\
\hline
\end{tabular}

Legend: $\rho_{S}=$ correlation between the supply shocks, $\lambda_{G}^{B}=$ baseline value for $\lambda_{G}, L^{c}=$ loss under commitment with full optimization, $L^{d}=$ idem for discretion, $L^{c p}=$ loss under commitment with fiscal policy restricted to $\widehat{G}_{t}^{i}=\widetilde{G}_{t}^{i}(i=H, F), L^{d p}=$ idem for discretion, $L^{r}=$ loss under indicated monetary rule and fiscal rule (36) with $g_{C H}=g_{C F}=0$ imposed; $L^{r p}=$ loss under indicated monetary rule with passive fiscal policy; $\left(g_{T H}^{o p t}, g_{T F}^{\text {opt }}\right)=$ optimal combination of fiscal policy coefficients under this rule. All losses have been multiplied by 10000.

Note: the results for the rules all assume that monetary policy is characterized by the rule (35) with parameter values $\left(b_{H}, b_{F}, b_{C}, b_{T}, d^{H}, d^{F}\right)=(0,0,75,0,125,125)$. 
Table 2: Expected welfare losses relative to commitment with full optimization. Measured as corresponding permanent change in the consumption gap (in \%).

\begin{tabular}{|l|l|l|l|l|l|}
\hline$\left(\alpha^{H}, \rho_{S}, \eta, \lambda_{G}\right)$ & $D$ & $C P$ & $D P$ & $R$ & $R P$ \\
\hline \hline baseline & 0.56 & 0.63 & 0.63 & 0.37 & 0.63 \\
\hline$\left(0.75,0.5,10, \lambda_{G}^{B}\right)$ & 0.39 & 0.45 & 0.45 & 0.26 & 0.45 \\
\hline$\left(0.75,-1,10, \lambda_{G}^{B}\right)$ & 0.77 & 0.90 & 0.90 & 0.52 & 0.90 \\
\hline$\left(0.5,0,10, \lambda_{G}^{B}\right)$ & 0.42 & 0.48 & 0.52 & 0.33 & 0.53 \\
\hline$\left(0.5,-1,10, \lambda_{G}^{B}\right)$ & 0.59 & 0.68 & 0.73 & 0.47 & 0.75 \\
\hline \hline$\left(0.75,0,10, \frac{1}{2} \lambda_{G}^{B}\right)$ & 0.68 & 0.80 & 0.80 & 0.41 & 0.80 \\
\hline$\left(0.75,-1,10, \frac{1}{2} \lambda_{G}^{B}\right)$ & 0.96 & 1.13 & 1.13 & 0.58 & 1.13 \\
\hline$\left(0.5,0,10, \frac{1}{2} \lambda_{G}^{B}\right)$ & 0.48 & 0.61 & 0.64 & 0.35 & 0.65 \\
\hline$\left(0.5,-1,10, \frac{1}{2} \lambda_{G}^{B}\right)$ & 0.68 & 0.86 & 0.90 & 0.50 & 0.92 \\
\hline \hline$\left(0.75,0,10,2 \lambda_{G}^{B}\right)$ & 0.43 & 0.48 & 0.48 & 0.31 & 0.48 \\
\hline$\left(0.75,-1,10,2 \lambda_{G}^{B}\right)$ & 0.61 & 0.68 & 0.68 & 0.43 & 0.68 \\
\hline$\left(0.5,0,10,2 \lambda_{G}^{B}\right)$ & 0.34 & 0.36 & 0.41 & 0.30 & 0.43 \\
\hline$\left(0.5,-1,10,2 \lambda_{G}^{B}\right)$ & 0.49 & 0.51 & 0.58 & 0.42 & 0.60 \\
\hline \hline$\left(0.75,0,5, \lambda_{G}^{B}\right)$ & 0.43 & 0.49 & 0.49 & 0.30 & 0.49 \\
\hline$\left(0.75,-1,5, \lambda_{G}^{B}\right)$ & 0.61 & 0.70 & 0.70 & 0.42 & 0.70 \\
\hline
\end{tabular}

Legend: $D=$ full optimization under discretion, $C P=$ optimal monetary policy under commitment and passive fiscal policy, $D P=$ optimal monetary policy under discretion and passive fiscal policy, $R=$ monetary policy rule aimed at closing world consumption gap and zero world inflation (see Table 1), while fiscal policy is set optimally according to (36) with $g_{C H}=g_{C F}=0$ imposed. $R P=$ idem for monetary policy, but with passive fiscal policy. 
Table 3: Expected welfare losses under the combination of rules (40) and (41).

\begin{tabular}{|l|l|l|l|l|l|}
\hline$\left(\alpha^{H}, \rho_{S}, \eta, \lambda_{G}\right)$ & $L^{r}$ & $R$ & $\left(g_{Y H}^{\text {opt }}, g_{Y F}^{\text {opt }}\right)$ & $L^{r p}$ & $R P$ \\
\hline \hline baseline & 0.6947 & 0.38 & $(1.29,1.29)$ & 0.7421 & 0.64 \\
\hline$\left(0.75,0.5,10, \lambda_{G}^{B}\right)$ & 0.3478 & 0.27 & $(1.29,1.29)$ & 0.3714 & 0.45 \\
\hline$\left(0.75,-1,10, \lambda_{G}^{B}\right)$ & 1.3886 & 0.53 & $(1.29,1.29)$ & 1.4834 & 0.90 \\
\hline$\left(0.5,0,10, \lambda_{G}^{B}\right)$ & 0.8510 & 0.39 & $(2.14,0.94)$ & 0.9149 & 0.60 \\
\hline$\left(0.5,-1,10, \lambda_{G}^{B}\right)$ & 1.6813 & 0.49 & $(2.14,0.96)$ & 1.8096 & 0.81 \\
\hline \hline$\left(0.75,0,10, \frac{1}{2} \lambda_{G}^{B}\right)$ & 0.6571 & 0.41 & $(2.83,2.83)$ & 0.7421 & 0.80 \\
\hline$\left(0.75,-1,10, \frac{1}{2} \lambda_{G}^{B}\right)$ & 1.3133 & 0.58 & $(2.83,2.83)$ & 1.4834 & 1.13 \\
\hline$\left(0.5,0,10, \frac{1}{2} \lambda_{G}^{B}\right)$ & 0.8055 & 0.38 & $(4.49,2.02)$ & 0.9149 & 0.71 \\
\hline$\left(0.5,-1,10, \frac{1}{2} \lambda_{G}^{B}\right)$ & 1.5896 & 0.47 & $(4.49,2.06)$ & 1.8096 & 0.97 \\
\hline \hline$\left(0.75,0,10,2 \lambda_{G}^{B}\right)$ & 0.7171 & 0.31 & $(0.61,0.61)$ & 0.7421 & 0.48 \\
\hline$\left(0.75,-1,10,2 \lambda_{G}^{B}\right)$ & 1.4334 & 0.43 & $(0.61,0.61)$ & 1.4834 & 0.68 \\
\hline$\left(0.5,0,10,2 \lambda_{G}^{B}\right)$ & 0.8802 & 0.38 & $(1.03,0.44)$ & 0.9149 & 0.51 \\
\hline$\left(0.5,-1,10,2 \lambda_{G}^{B}\right)$ & 1.7400 & 0.48 & $(1.03,0.45)$ & 1.8096 & 0.67 \\
\hline \hline$\left(0.75,0,5, \lambda_{G}^{B}\right)$ & 0.6209 & 0.30 & $(1.11,1.11)$ & 0.6537 & 0.50 \\
\hline$\left(0.75,-1,5, \lambda_{G}^{B}\right)$ & 1.2411 & 0.42 & $(1.11,1.11)$ & 1.3067 & 0.70 \\
\hline
\end{tabular}

Legend: $L^{r}=$ welfare loss under optimal fiscal rule, $R=$ welfare loss relative to full commitment under the optimal fiscal rule expressed as a permanent change in the consumption gap (in \%-points), $\left(g_{Y H}^{\text {opt }}, g_{Y F}^{o p t}\right)=$ optimal combination of $\left(g_{Y H}, g_{Y F}\right), L^{r p}=$ welfare loss when fiscal policy is passive $\left(g_{Y H}=g_{Y F}=0\right)$ and $R P=$ welfare loss relative to full commitment expressed as a permanent change in the consumption gap (in \%-points) when fiscal policy is passive. (All losses have been multiplied by 10000.)

Table 4: Expected welfare losses under the combination of rules (40) and (41): allowing for different weights on Home and Foreign inflation.

\begin{tabular}{|l|l|l|l|}
\hline$\left(\alpha^{H}, \rho_{S}, \lambda_{G}\right)$ & $\left(g_{Y H}, g_{Y F}\right)$ & $\left(\delta_{H}^{o p t}, \delta_{F}^{o p t}\right)$ & $L^{d w}$ \\
\hline \hline$\left(0.5,0, \lambda_{G}^{B}\right)$ & $(0,0)^{a}$ & $(0.490,0.510)$ & 0.9148 \\
\hline$\left(0.5,-1, \lambda_{G}^{B}\right)$ & $(0,0)^{a}$ & $(0.491,0.509)$ & 1.8094 \\
\hline$\left(0.5,0, \lambda_{G}^{B}\right)$ & $(2.14,0.94)^{b}$ & $(0.493,0.507)$ & 0.8510 \\
\hline$\left(0.5,-1, \lambda_{G}^{B}\right)$ & $(2.14,0.96)^{b}$ & $(0.494,0.506)$ & 1.6812 \\
\hline$\left(0.5,0, \frac{1}{2} \lambda_{G}^{B}\right)$ & $(4.49,2.02)^{b}$ & $(0.490,0.510)$ & 0.8054 \\
\hline$\left(0.5,-1, \frac{1}{2} \lambda_{G}^{B}\right)$ & $(4.49,2.06)^{b}$ & $(0.490,0.510)$ & 1.5894 \\
\hline$\left(0.5,0,2 \lambda_{G}^{B}\right)$ & $(1.03,0.44)^{b}$ & $(0.493,0.507)$ & 0.8802 \\
\hline$\left(0.5,-1,2 \lambda_{G}^{B}\right)$ & $(1.03,0.45)^{b}$ & $(0.494,0.506)$ & 1.7399 \\
\hline
\end{tabular}

Legend: $\left(g_{Y H}, g_{Y F}\right)=$ coefficients in $(41),\left(\delta_{H}^{o p t}, \delta_{F}^{o p t}\right)=$ optimized coefficients in (40), $L^{d w}=$ associated welfare loss (multiplied by 10000).

Notes: $a$ : Coefficients constrained to zero; $b$ : optimized coefficients taken from corresponding parameter setting in Table 3 . 


\section{References}

[1] Alesina, A., S. Ardagna, R. Perotti and F. Schiantarelli, 1999, Fiscal Policy, Profits, and Investment, NBER Working Paper No. 7207.

[2] Andrés, J., J. D. López-Salido and J. Vallés, 2001, Money in an Estimated Business Cycle Model of the Euro Area, Documento de Trabajo no. 0121, Banco de España.

[3] Aoki, K., 2002, Optimal Monetary Policy Responses to Relative-Price Changes, Journal of Monetary Economics 48, 55-80.

[4] Backus, D.B. and J. Driffill, 1986, The Consistency of Optimal Policy in Stochastic Rational Expectations Models, CEPR Discussion Paper, No. 124, London.

[5] Beetsma, R.M.W.J. and P.C. Schotman, 2001, Measuring Risk Attitudes in a Natural Experiment: Data from the Television Game Show LINGO, Economic Journal 111, $474,821-848$.

[6] Benigno, P., 2001, Optimal Monetary Policy in a Currency Area, mimeo, Princeton University.

[7] Benigno, P., 2002, Appropriate Country Weights for Inflation Targeting in the European Monetary Union, C.V. Starr Center Newsletter 18, 11-12.

[8] Benigno, G. and P. Benigno, 2001, Implementing Monetary Policy Cooperation through Inflation Targeting, mimeo, Bank of England/New York University.

[9] Calvo, G., 1983, Staggered Prices in a Utility-Maximizing Framework, Journal of Monetary Economics 12, 383-98.

[10] Canzoneri, M.B., Cumby, R.E. and B.T. Diba, 2002, The Need for International Policy Coordination: What's Old, What's New, What's yet to Come?, NBER Working Paper, No. 8765.

[11] Clarida, R., J. Galí and M. Gertler, 1999, The Science of Monetary Policy: A New Keynesian Perspective, Journal of Economic Literature 27, 1661-1707.

[12] Clarida, R., Galí, J. and M. Gertler, 2002, A Simple Framework for International Monetary Policy Analysis, CEPR Discussion Paper, No. 3355, London.

[13] Coenen, G. and V. Wieland, 2000, A Small Estimated Euro Area Model with Rational Expectations and Nominal Rigidities, European Central Bank, Working Paper No. 30, Frankfurt.

[14] Cooley, T. F. and E. Prescott, 1995, Economic Growth and Business Cycles, in T. F. Cooley (ed.), Frontiers of Business Cycle Research, Princeton University Press, Princeton, NJ. 
[15] Corsetti, G. and P. Pesenti, 2001a, Welfare and Macroeconomic Interdependence, Quarterly Journal of Economics 116, 2, 421-446.

[16] Corsetti, G. and P. Pesenti, 2001b, The International Dimension of Optimal Monetary Policy, NBER Working Paper, No. 8230.

[17] Devereux, M. B., 1991, The Terms of Trade and the International Coordination of Fiscal Policy, Economic Inquiry 29, 720-36.

[18] Dixit, A. and J. E. Stiglitz, 1977, Monopolistic Competition and Optimum Product Diversity, American Economic Review 67, 297-308.

[19] Erceg, C.J., Henderson, D.W. and A.T. Levin, 2000, Optimal Monetary Policy with Staggered Wage and Price Contracts, Journal of Monetary Economics 46, 281-313.

[20] Fatás, A. and I. Mihov, 2000, Fiscal Policy and Business Cycles: An Empirical Investigation, mimeo, INSEAD.

[21] Fatás, A. and I. Mihov, 2001, The Effects of Fiscal Policy on Consumption and Employment: Theory and Evidence, CEPR Discussion Paper, No. 2760.

[22] Finn, M. G., 1998, Cyclical Effects of Government's Employment and Goods Purchases, International Economic Review 39, 635-57.

[23] Galí, J. and M. Gertler, 1999, Inflation Dynamics: A Structural Econometric Analysis, Journal of Monetary Economics 44, 195-222.

[24] Galí, J., Gertler, M. and J.D. López-Salido, 2001, European Inflation Dynamics, European Economic Review 45, 1237-1270.

[25] Ireland, P., 2000, Money's Role in the Monetary Business Cycle, mimeo, Boston College.

[26] Lane, P.R., 1998, On the Cyclicality of Irish Fiscal Policy, The Economic and Social Review 29, 1-16.

[27] Lane, P.R., 2002, The Cyclical Behaviour of Fiscal Policy: Evidence from the OECD, Journal of Public Economics, forthcoming.

[28] Neiss, K. and E. Nelson, 2002, Inflation Dynamics, Marginal Cost, and the Output Gap: Evidence from Three Countries, mimeo, Bank of England.

[29] Obstfeld, M. and K. Rogoff, 2002, Global Implications of Self-Oriented National Monetary Rules, Quarterly Journal of Economics 117, 503-535.

[30] Roberts, J. M., 1995, New Keynesian Economics and the Phillips Curve, Journal of Money, Credit, and Banking 27, 975-84. 
[31] Sbordone, A.G., 2002, Prices and Unit Labor Costs: A New Test of Price Stickiness, Journal of Monetary Economics 49, 265-292.

[32] Schmitt-Grohé, S. and M. Uribe, 2001, Optimal Fiscal and Monetary Policy under Sticky Prices, CEPR Discussion Paper, No. 2942.

[33] Sims, C., 1999, The Precarious Fiscal Foundations of EMU, De Economist 147, 41536.

[34] Söderlind, P., 1999, Solution and Estimation of RE Macromodels with Optimal Policy, European Economic Review 43, 813-23.

[35] Sutherland, A., 2002, Cost-Push Shocks and the Optimal Choice of Monetary Target in an Open Economy, mimeo, University of St. Andrews.

[36] Svensson, L.E.O., 1994, Why Exchange Rate Bands? Monetary Independence in Spite of Fixed Exchange Rates, Journal of Monetary Economics 33, 157-199.

[37] Svensson, L.E.O., 2001, What Is Wrong with Taylor Rules? Using Judgement in Monetary Policy through Targeting Rules, mimeo, Princeton University.

[38] Taylor, J. B., 1993, Discretion versus Rules in Practice, Carnegie-Rochester Series on Public Policy 39, 195-214.

[39] Taylor, J. B. (ed.), 1999, Monetary Policy Rules (University of Chicago Press).

[40] Turnovsky, S. J., 1988, The Gains from Fiscal Cooperation in the Two-Commodity Real Trade Model, Journal of International Economics 25, 111-27.

[41] Woodford, M., 1999a, Optimal Monetary Policy Inertia, NBER Working Paper, No. 7261 .

[42] Woodford, M., 1999b, Commentary: How Should Monetary Policy Be Conducted in an Era of Price Stability?, in New Challenges for Monetary Policy, A symposium sponsored by the Federal Reserve Bank of Kansas City, 277-316.

[43] Woodford, M., 2002, Interest and Prices: Foundations of a Theory of Monetary Policy, book manuscript, Princeton University.

[44] Wynne, M. A., 1996, Balanced Budget Multipliers, Journal of Macroeconomics 18, 197-211. 


\section{European Central Bank working paper series}

For a complete list of Working Papers published by the ECB, please visit the ECB's website (http://www.ecb.int).

II3 "Financial frictions and the monetary transmission mechanism: theory, evidence and policy implications” by C. Bean, J. Larsen and K. Nikolov, January 2002.

II4 "Monetary transmission in the euro area: where do we stand?" by I. Angeloni, A. Kashyap, B. Mojon, D. Terlizzese, January 2002.

I 5 "Monetary policy rules, macroeconomic stability and inflation: a view from the trenches" by A. Orphanides, December 2001 .

II6 "Rent indices for housing in West Germany 1985 to 1998" by J. Hoffmann and C. Kurz., January 2002.

117 "Hedonic house prices without characteristics: the case of new multiunit housing" by O. Bover and P. Velilla, January 2002.

I 18 "Durable goods, price indexes and quality change: an application to automobile prices in Italy, 1988-1998” by G. M. Tomat, January 2002.

I 19 "Monetary policy and the stock market in the euro area" by N. Cassola and C. Morana, January 2002.

120 "Learning stability in economics with heterogenous agents" by S. Honkapohja and K. Mitra, January 2002.

I2I “Natural rate doubts” by A. Beyer and R. E. A. Farmer, February 2002.

122 "New technologies and productivity growth in the euro area" by F. Vijselaar and R. Albers, February 2002.

123 "Analysing and combining multiple credit assessments of financial institutions" by E. Tabakis and A. Vinci, February 2002.

124 "Monetary policy, expectations and commitment" by G. W. Evans and S. Honkapohja, February 2002.

125 “Duration, volume and volatility impact of trades" by S. Manganelli, February 2002.

126 "Optimal contracts in a dynamic costly state verification model" by C. Monnet and E. Quintin, February 2002.

127 "Performance of monetary policy with internal central bank forecasting" by S. Honkapohja and K. Mitra, February 2002.

128 "Openness, imperfect exchange rate pass-through and monetary policy" by F. Smets and R. Wouters, February 2002. 
129 "Non-standard central bank loss functions, skewed risks, and certainty equivalence" by A. al-Nowaihi and L. Stracca, March 2002.

130 "Harmonized indexes of consumer prices: their conceptual foundations" by E. Diewert, March 2002.

131 "Measurement bias in the HICP: what do we know, and what do we need to know?" by M. A. Wynne and D. Rodríguez-Palenzuela, March 2002.

132 "Inflation dynamics and dual inflation in accession countries: a "new Keynesian" perspective" by O. Arratibel, D. Rodríguez-Palenzuela and C. Thimann, March 2002.

133 "Can confidence indicators be useful to predict short term real GDP growth?" by A. Mourougane and M. Roma, March 2002.

134 "The cost of private transportation in the Netherlands, 1992-1999" by B. Bode and J. Van Dalen, March 2002.

135 "The optimal mix of taxes on money, consumption and income" by F. De Fiore and P. Teles, April 2002.

136 "Retail bank interest rate pass-through: the new evidence at the euro area level" by G. de Bondt, April 2002.

137 "Equilibrium bidding in the eurosystem's open market operations" by U. Bindseil, April 2002.

138 "New" views on the optimum currency area theory: what is EMU telling us?" by F. P. Mongelli, April 2002.

139 "On currency crises and contagion" by M. Fratzscher, April 2002.

140 "Price setting and the steady-state effects of inflation" by M. Casares, May 2002.

14I "Asset prices and fiscal balances" by F. Eschenbach and L. Schuknecht, May 2002.

142 "Modelling the daily banknotes in circulation in the context of the liquidity management of the European Central Bank", by A. Cabrero, G. Camba-Mendez, A. Hirsch and F. Nieto, May 2002.

143 “A non-parametric method for valuing new goods", by I. Crawford, May 2002.

144 "A failure in the measurement of inflation: results from a hedonic and matched experiment using scanner data", by M. Silver and S. Heravi, May 2002.

145 "Towards a new early warning system of financial crises", by M. Fratzscher and M. Bussiere, May 2002.

I46 “Competition and stability - what's special about banking?", by E. Carletti and P. Hartmann, May 2002. 
147 "Time-to-build approach in a sticky price, stricky wage optimizing monetary model, by M. Casares, May 2002.

148 "The functional form of yield curves" by V. Brousseau, May 2002.

149 "The Spanish block of the ESCB-multi-country model" by A. Estrada and A. Willman, May 2002.

150 "Equity and bond market signals as leading indicators of bank fragility" by R. Gropp, J. Vesala and G. Vulpes, June 2002.

I5I "G-7 inflation forecasts" by F. Canova, June 2002.

152 "Short-term monitoring of fiscal policy discipline" by G. Camba-Mendez and A. Lamo, June 2002.

153 "Euro area production function and potential output: a supply side system approach" by A. Willman, June 2002.

154 "The euro bloc, the dollar bloc and the yen bloc: how much monetary policy independence can exchange rate flexibility buy in an interdependent world?" by M. Fratzscher, June 2002.

155 "Youth unemployment in the OECD: demographic shifts, labour market institutions, and macroeconomic shocks" by J. F. Jimeno and D. Rodriguez-Palenzuela, June 2002.

156 "Identifying endogenous fiscal policy rules for macroeconomic models" by J. J. Perez, and P. Hiebert, July 2002.

157 "Bidding and performance in repo auctions: evidence from ECB open market operations" by K. G. Nyborg, U. Bindseil and I. A. Strebulaev, July 2002.

I58 "Quantifying Embodied Technological Change” by P. Sakellaris and D. J. Wilson, July 2002.

159 “Optimal public money” by C. Monnet, July 2002.

160 "Model uncertainty and the equilibrium value of the real effective euro exchange rate" by C. Detken, A. Dieppe, J. Henry, C. Marin and F. Smets, July 2002.

16I "The optimal allocation of risks under prospect theory" by L. Stracca, July 2002.

162 "Public debt asymmetries: the effect on taxes and spending in the European Union" by S. Krogstrup, August 2002.

163 "The rationality of consumers' inflation expectations: survey-based evidence for the euro area" by M. Forsells and G. Kenny, August 2002.

164 "Euro area corporate debt securities market: first empirical evidence" by G. de Bondt, August 2002. 
165 "The industry effects of monetary policy in the euro area" by G. Peersman and F. Smets, August 2002.

166 "Monetary and fiscal policy interactions in a micro-founded model of a monetary union" by R. M.W.J. Beetsma and H. Jensen, August 2002. 